\title{
The research into the propagation law of the shock wave of a gas explosion inside a building
}

\author{
Shu-Chao Lin, ${ }^{1,2,3}$ You-Chun Xu, ${ }^{1}$ Pei-Dong Yang, ${ }^{1}$ Shan Gao ${ }^{1},{ }^{4,5}$ Yi-Jun Zhou, ${ }^{3}$ \\ and Jin $\mathrm{Xu}^{1}$ \\ ${ }^{1}$ Shaanxi Key Laboratory of Safety and Durability of Concrete Structures, Xijing University, Xi'an 710123, China \\ ${ }^{2}$ Post-Doctoral Mobile Station of Civil Engineering, School of Civil Engineering, Tianjin University, Tianjin 300072, China \\ ${ }^{3}$ College of Civil and Architectural Engineering, North China University of Science and Technology, Tangshan 063210, China \\ ${ }^{4}$ School of Civil Engineering, Harbin Institute of Technology, Harbin 150000, China \\ ${ }^{5}$ Postdoctoral Station of Civil Engineering, Chongqing University, Chongqing 400000, China \\ Correspondence should be addressed to Shan Gao; 13833185232@139.com
}

Received 21 June 2021; Revised 29 July 2021; Accepted 23 September 2021; Published 7 October 2021

Academic Editor: Arturo Garcia-Perez

Copyright (c) 2021 Shu-Chao Lin et al. This is an open access article distributed under the Creative Commons Attribution License, which permits unrestricted use, distribution, and reproduction in any medium, provided the original work is properly cited.

\begin{abstract}
Based on the dissipation rate conservation equations of turbulent kinetic energy in the k- $\varepsilon$ turbulence model, a complicated threedimensional finite element model of a kitchen filled with gas mixture is developed by using the open source field operation and manipulation (OpenFOAM). Two representative kitchens were used to investigate the propagation law of the shock wave of a gas explosion inside a building by considering the key characteristics of the blast shock wave. The influence of some crucial parameters, such as initial conditions and kitchen parameters, on the properties of the blast shock wave is investigated. The basic steps to predict the peak pressure of the blast shock wave are given in consideration of the initial condition and the kitchen whilst the injury effect of the blast shock wave on the humans and animals is evaluated. The research results indicate that the pressure time history and the peak pressure space distribution are greatly influenced by the kitchen design layout. The coupled interaction between the initial temperature and gas volume concentration, especially at the upper and lower explosion limits of the gas, significantly affects the peak pressure. The peak pressure varies significantly with the opening and the buffer; however, it has little relation with the width, length, and height of the kitchen. The proposed method can accurately and effectively predict the peak pressure of the blast shock wave inside buildings. In terms of the peak pressure space distribution of the explosion shock wave, the peak pressure is much higher than the threshold of the killing pressure, which is unsafe for the humans and animals in the building.
\end{abstract}

\section{Introduction}

With the acceleration of the urbanization process, urban gas gradually becomes an important part of the energy in citizen's daily life over the last few decades $[1,2]$ resulting from its irreplaceable advantages, such as high efficiency, cleanness and cheapness. Urban gases mainly include natural gas, manufactured gas, liquefied petroleum gas and marsh gas which are flammable and explosive. Urban gas leakage in the process of being used is very likely to cause an explosion inside a building and easily leads to a chain of disastrous consequences $[3,4]$. Therefore, the research into the propagation law of the shock wave of a gas explosion inside buildings has been widely concerned by the researchers and engineers in this field [5].

Many theoretical analyses, experiment studies and numerical simulations have been conducted to investigate the injury effect on the living beings based on North Atlantic Treaty Organization and Department of Defense specifications $[6,7]$. The basic characteristics of the blast shock wave in free air have been investigated, such as the time and space attenuation model of the pressure $[8]$ and the impulse $[8,9]$. However, the researches concerning the propagation law of the blast shock wave caused by an explosive charge or gas explosion inside a building are few. As far as the building structures are concerned, considering the multiple 
propagation patterns of the blast shock wave and the geometrical conditions of the underground transportation infrastructure, Pennetier et al. [10] determined the position of this transition spherical-to-planar wave propagation in a tunnel using both numerical simulations and scale model tests and verified the dedicated law proposed by himself. By considering the effects of stairs, pillars, and wall materials, $\mathrm{Ma}$ et al. [11] discussed the propagation law of the blast shock wave in a metro station, and estimated the harm on the human health. A few prevention measures against an explosion scenario to reduce the killing effect on the humans were proposed. Edri et al. [12] conducted experimental, analytical, and numerical studies to investigate an explosion in an enclosed space, which significantly benefitted the advancement of knowledge regarding this subject.

Additionally, the studies regarding the propagation law of the blast shock wave resulted from a gas explosion are very few. By using the reliable commercial computational fluid dynamics (CFD) software FLACS, Ji and Wang [13, 14] successfully predicted the formation process of the natural gas cloud due to the pipeline leakage inside and outside the building and accurately reproduced the gas explosion accident scene that had happened. With the help of the CFD numerical simulation method, Wang et al. [15] mainly analyzed the gas leakage and diffusion, blast shock wave, and flame propagation process of a real gas explosion inside the building, and discussed about the reason for this accident through it. Based on the characteristics of the building structure, Li et al. [16] proposed a hybrid method that combines the numerical simulation and the analytical solutions to predict the internal and external pressures from the vented gas explosion in a large enclosure, and verified the reliability and accuracy of this method by the experimental data.

From the aforementioned reference review, the existing researches on this subject mainly concentrate on the propagation process of the blast shock wave in a particular space, but lack of the properties of the blast shock wave itself. Concurrently, several research problems associated with the propagation law of the blast shock wave caused by a gas explosion remain unclear as a result of the limitations of the study subjects and the experimental conditions.

In view of the above and some typical urban gas explosion incidents $[13-15,17]$ in recent years, a series of numerical simulation analyses are conducted on kitchen to investigate the influence of the initial condition on the properties of the blast shock wave. A new method is proposed herein to estimate the properties of the blast shock wave inside the building. This present study can provide the technological support and theoretical basis for the potential risk assessment on the living beings [18].

\section{Finite element model of the kitchen}

2.1. Kitchen scheme. In order to explore the propagation law of the shock wave of a gas explosion inside a building, two representative kitchens [19-22] are introduced in this study, as shown in Figure 1. As far as Scheme 1 is concerned, the kitchen is enclosed on three sides by the filling wall and faces the dining and living room on the fourth side. It can be defined by three parameters: kitchen width, $w_{k}=2500 \mathrm{~mm}$; kitchen length, $l_{k}=2500 \mathrm{~mm}$; and kitchen height, $h_{k}=$ $3600 \mathrm{~mm}$. As for Scheme 2, three sides are also surrounded by the filling wall and one side is adjacent to the buffer zone, which is often used as the toilet, storage room, etc. It can be defined by four parameters: kitchen width, $w_{k}=2500 \mathrm{~mm}$; kitchen length, $l_{k}=2500 \mathrm{~mm}$; kitchen height, $h_{k}=3600 \mathrm{~mm}$; and buffer length, $l_{b}=2000 \mathrm{~mm}$. The dimensions of the door and window openings are $1000 \mathrm{~mm} \times 2400 \mathrm{~mm}$ and $900 \mathrm{~mm} \times 1800 \mathrm{~mm}$, respectively. Thus, the window hole ratio of the wall is as follows: $\lambda_{k}=18 \%$. The air is mixed with the urban gas in certain proportion to form the gas mixture with the initial temperature of $25{ }^{\circ} \mathrm{C}$ and initial pressure of $101.325 \mathrm{kPa}$. The kitchen is filled with the gas mixture that is ignited with temperature of $2000{ }^{\circ} \mathrm{C}$ at the center of it.

2.2. Basic theory. Along with the development of modern computers, the computational fluid dynamics is widely used in solving a variety of complicated problems in fluid mechanics. It can accurately predict a wide range of physical phenomena of the fluid, such as fluid flow, heat transfer, mass transfer, chemical reaction and so on.

2.2.1. Governing equations. Urban gas explosion in the kitchen can be regard as a swift and violent combustion process [23]. This section describes the mathematical model for it, which mainly includes a set of the governing equations [24, 25], such as the equations for conservation of mass, momentum, energy, chemical specie, turbulent kinetic energy and its dissipation rate. In the Cartesian coordinate system, these equations are presented in partial differential form as follow.

The mass conservation equation (continuity equation) is:

$$
\frac{\partial}{\partial t}(\rho)+\frac{\partial}{\partial x_{i}}\left(\rho v_{i}\right)=0
$$

where $\rho$ is the mass density; $v_{j}$ is the velocity component in $i$-direction; $x_{j}$ is the global Cartesian coordinate; and $t$ is the time.

The momentum conservation equation (Navier-Stokes equation) is:

$$
\frac{\partial}{\partial t}\left(\rho v_{j}\right)+\frac{\partial}{\partial x_{i}}\left(\rho v_{i} v_{j}\right)=\frac{\partial}{\partial x_{j}}(p)+\frac{\partial}{\partial x_{i}}\left(\tau_{i j}\right)+\rho \sum_{k=1}^{N} Y_{k} f_{k, j} \text {, }
$$

where $p$ is the static pressure; $\tau_{i j}$ is the deviatoric stress tensor; $Y_{k}$ is the mass fraction of chemical specie $k$; and $f_{k, j}$ is the volume force acting on the chemical specie $k$ in $j$-direction.

In the above equation, the deviatoric stress tensor can be defined as follows:

$$
\tau_{i j}=-\frac{2}{3} \mu \frac{\partial v_{k}}{\partial x_{k}} \delta_{i j}+\mu\left(\frac{\partial v_{i}}{\partial x_{j}}+\frac{\partial v_{j}}{\partial x_{i}}\right)
$$




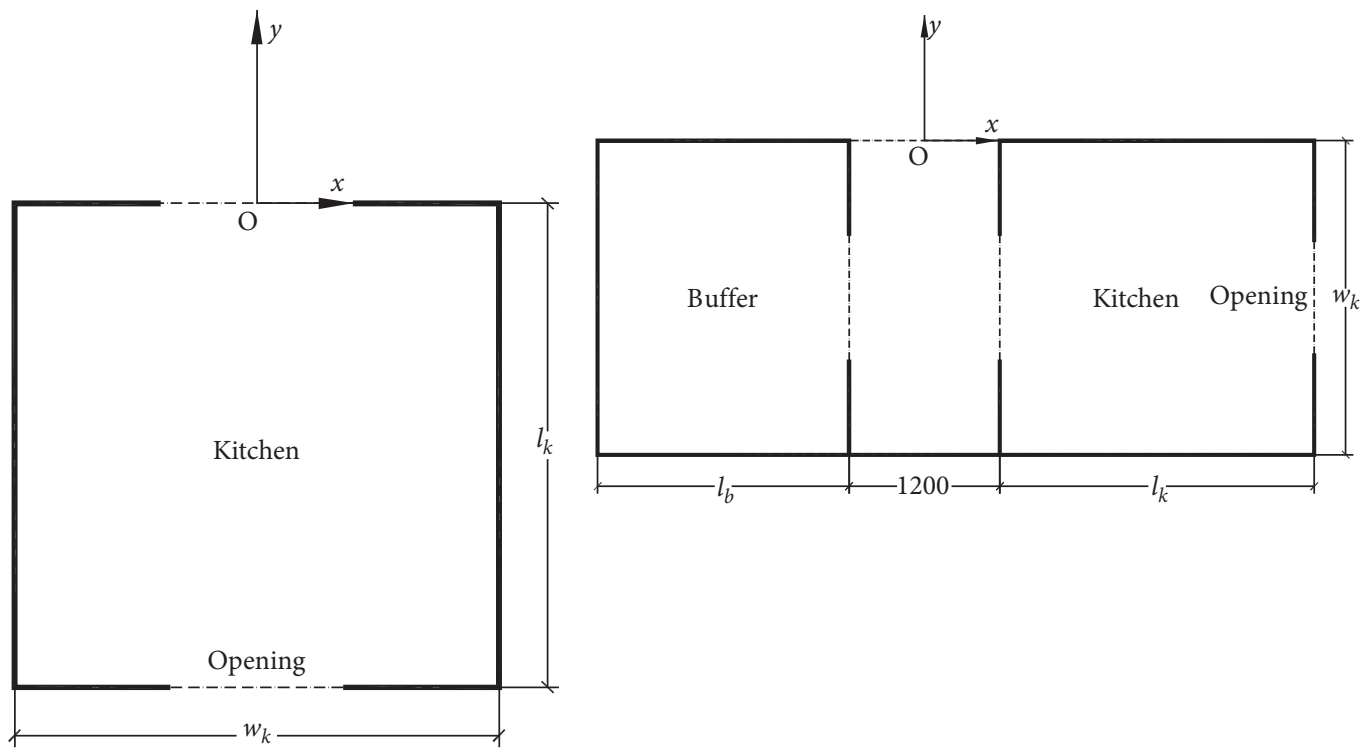

(a)

(b)

FIGURE 1: Kitchen prototype. (a) Scheme 1 (b) Scheme 2

where $\mu$ is the dynamic viscosity; and $\delta_{i j}$ is the Kronecker Delta function.

The energy (enthalpy) conservation equation is:

$$
\frac{\partial}{\partial t}(\rho h)+\frac{\partial}{\partial x_{i}}\left(\rho v_{i} h\right)=\frac{D p}{D t}-\frac{\partial q_{i}}{\partial x_{i}}+\tau_{i j} \frac{\partial u_{i}}{\partial x_{j}}+\dot{Q}+\rho \sum_{k=1}^{N} Y_{k} f_{k, i} V_{k, i} \text {, }
$$

where $h$ is the enthalpy; $D / D t$ is the substantial derivative operator; $q_{i}$ is the energy flux; $\dot{Q}$ is the heat source term; and $V_{k, i}$ is the $i$-component of the diffusion velocity $V_{k}$ of chemical specie $k$.

The conservation equation of mass fraction of chemical specie is:

$$
\frac{\partial}{\partial t}\left(\rho Y_{k}\right)+\frac{\partial}{\partial x_{i}}\left[\rho\left(v_{i}+V_{k, i}\right) Y_{k}\right]=\dot{w}_{k}
$$

where $\dot{w}_{k}$ is the reaction rate of chemical specie $k$.

In addition, the turbulent kinetic energy and its dissipation rate conservation equations [26] need to be satisfied in the $\mathrm{k}-\varepsilon$ turbulence model, and can be written as follows:

$$
\begin{aligned}
& \frac{\partial}{\partial t}(\rho k)+\frac{\partial}{\partial x_{i}}\left(\rho v_{i} k\right)=\frac{\partial}{\partial x_{i}}\left[\left(\mu+\frac{\mu_{t}}{\sigma_{k}}\right) \frac{\partial k}{\partial x_{i}}\right]+P_{k}-\rho \varepsilon, \\
& \frac{\partial}{\partial t}(\rho \varepsilon)+\frac{\partial}{\partial x_{i}}\left(\rho v_{i} \varepsilon\right)=\frac{\partial}{\partial x_{i}}\left[\left(\mu+\frac{\mu_{t}}{\sigma_{\varepsilon}}\right) \frac{\partial \varepsilon}{\partial x_{i}}\right]+\frac{\varepsilon}{k}\left(C_{1} P_{k}-C_{2} \rho \varepsilon\right),
\end{aligned}
$$

where $k$ and $\varepsilon$ are the turbulent kinetic energy and its dissipation rate, respectively; $\sigma_{k}$ and $\sigma_{\varepsilon}$ are the $k$ - $\varepsilon$ model constants, respectively; $\mu_{t}$ is the turbulent viscosity; $P_{k}$ is the production rate of the turbulent kinetic energy; and $C_{1}$ and $\mathrm{C}_{2}$ are all the non-dimensional constants.

The un-burnt gas is pushed ahead of the flame and the flame consumes the un-burnt gas. It produces a large amount of high temperature and high pressure gases in accompany with the complicated chemical kinetic equilibrium processes between these detonation products. Thus, the turbulent flow field is generated. The explosion pressure rises sharply and the detonation products expand dramatically. After that, the explosion pressure decreases greatly with the increase in volume expansion of the detonation products. Simultaneously, they are converted gradually to the ideal gas. This expansion can be up to 8-9 times the initial volume.

The equation of state of the detonation products is a complicated function of pressure, density and temperature. Up to now, the empirical or semi-empirical equation of state is mainly used. The main reason for this is that it is difficult to be determined directly by using the test method. The BKW equation of state [27] is introduced in this study and can be described as follows:

$$
\frac{p V_{m}}{R T}=1+x e^{\beta x}
$$

where

$$
\begin{aligned}
& x=\frac{k}{V_{m}(T+\theta)^{\alpha}}, \\
& k=\kappa \sum_{n=1}^{N} x_{n} k_{n} .
\end{aligned}
$$

Here $V_{m}$ is the molar gas volume; $R$ is the universal gas coefficient; $T$ is the absolute temperature; $x_{n}$ is the mole fraction of component $n$; and $\alpha, \beta, \kappa, \theta$, and $k_{n}$ are the constants.

The ideal gas is used in many applications of the existing finite element analysis software, for instance, FLACS, AutoReaGas, LS-DYNA and AUTODYN. The corresponding equation of state is derived from the laws of Boyle and Gay-Lussac [28] and can be expressed as follows: 


$$
p W_{m}=\rho R T,
$$

where $W_{m}$ is the molar weight of the gas mixture.

2.2.2. Other details. The solution algorithm used in the software OpenFOAM is the PIMPLE (merged PISO-SIMPLE) algorithm that is a combination of the pressure-implicit with splitting of operators (PISO) algorithm [29] and the semi-implicit method for pressure-linked equations (SIMPLE) algorithm. This algorithm has one predictor and two or three correctors. Thus, the mass and momentum conservation equations can be better satisfied, and simultaneously the convergence is accelerated at each iteration step. It is iterative procedure for solving the governing equations for the velocity and the pressure, which are used as the dependent variables. The practice has proved that it requires some extra storage space, but it is very fast and efficient. It is well-suited for the gas explosion scenario in OpenFOAM.

The turbulence models (e.g. standard $k-\varepsilon$ model, RNG Turbulence model, NKE Turbulence model, GIR Turbulence model, SZL Turbulence model, standard $k-\omega$ model, SST Turbulence model, etc.) are invalid immediately adjacent to the wall, since the viscous force dominates the inertial effect. Therefore, the wall function is introduced in this context to improve the modeling of the flow field in the near-wall region. The wall function has been tested on the low Reynolds number benchmark cases, and the good agreement between the published benchmark results and the OpenFOAM results is obtained [30].

The boundary conditions of the gas and air computation domain next to the filling wall and floor slab are the wall boundary for the velocity, meaning a fixed or stationary wall. All the others (including the door and window openings) are the zeroGradient boundary for the pressure, with the implication that the normal gradient of the pressure is the zero.

\section{Model validation}

In order to verify the validity of the finite element model and the corresponding analysis method, the propagation process of the shock wave of a methane/air or hydrogen/air mixture explosion reported in the reference [31] is simulated by using the finite element analysis method mentioned above.

In this validation study, there are two test chambers, which are measured to be $4.6 \mathrm{~m} \times 4.6 \mathrm{~m} \times 3.0 \mathrm{~m}$ and about $64 \mathrm{~m}^{3}$ in volume. They all have a square vent on the wall. Chamber I is $2.7 \mathrm{~m}^{2}$ and Chamber II is $5.4 \mathrm{~m}^{2}$. They are filled with the premixed hydrogen/air, methane/air or propane/air mixture, and the hydrogen, methane or propane gas volume concentration is about $18 \%, 9.5 \%$ or $4 \%$, respectively. There is one pressure sensor (PS) to monitor the pressure on the wall. PS is attached to the wall at a height of 1.5 meters above the ground, as depicted in Fig. 2. In addition, there are two ignition points (IP1 for Chamber I and IP2 for Chamber II) that are all at a height of $1.5 \mathrm{~m}$ above the ground, as shown in Figure 2. The electric ignition system is used in the gas explosion experiment, and

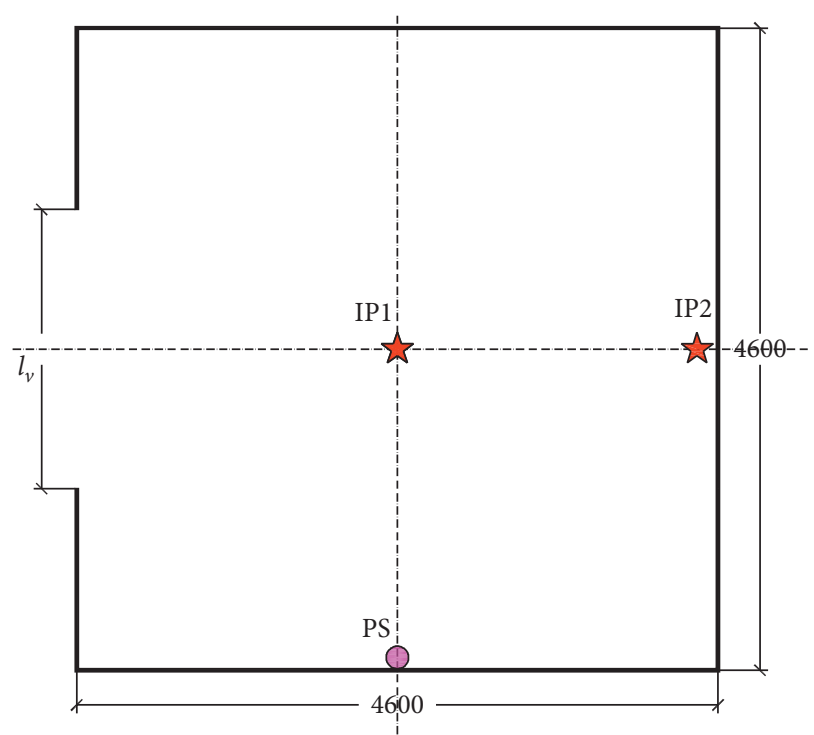

Figure 2: Test chamber.

the energy of the ignition is around $1000 \mathrm{~J}$. High-speed linescanning cameras are applied to capture more details of the gas explosion experiment.

Figure 3 describes the pressure time histories from experimental data and numerical simulation results. The maximum relative deviations between them are all less than $5 \%$ indicating that the numerical simulation results are in good agreement with the experimental data. There are three main reasons accounting for the difference between the test and simulated results. Firstly, the chamber is easy to deform slightly due to the gas explosion, thus affecting the measurement accuracy of the pressure sensor. Secondly, the ignition system is very hard to be simulated perfectly by using an ignition temperature. Thirdly, in general, a tiny quantity of the combustible and explosive gases of other type except the methane or hydrogen gas exists in the test.

\section{Characteristics of the blast shock wave}

Figure 4 describes the pressure time history of the blast shock wave of the measured point $\mathrm{O}$ in Fig. 1. The pressure increases immediately and reaches a maximum, after then it decreases rapidly, and gradually fluctuates around the zero, and finally tends to zero. It usually lasts for no more than $0.30 \mathrm{~s}$. The peak pressures of Schemes 1 and 2 are $160 \mathrm{kPa}$ and $97 \mathrm{kPa}$, respectively, and the peak pressure of Scheme 2 is only $61 \%$ of that of Scheme 1 . Hence, it can be concluded that the pressure time history is greatly influenced by the kitchen design layout [32].

Figure 5 depicts the peak pressure space distributions of Schemes 1 and 2 whilst $x$ and $y$ are the Cartesian coordinates, and $z=p / p_{O p}$, where $p$ and $p_{O p}$ are the peak pressures of the measured point $(x, y)$ and the measured point $\mathrm{O}$, respectively. It can be seen that the peak pressure decreases significantly with the distance away from the measured point $O$. In addition, the peak pressure space distribution is greatly influenced by the kitchen design layout [33]. 


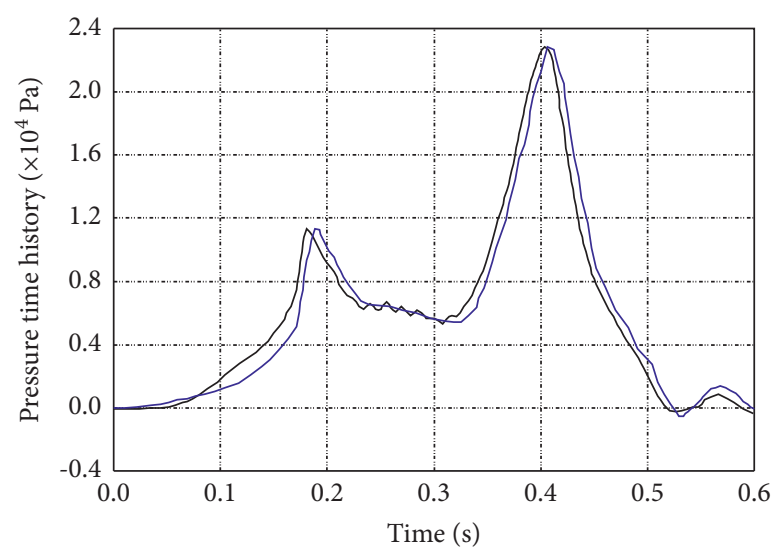

- Experimental data — Simulated results

(a)

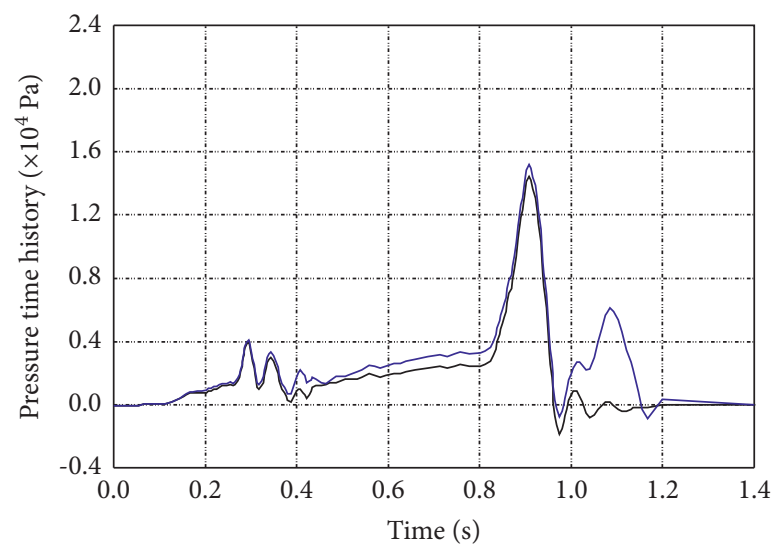

_ Experimental data

_ Simulated results

(c)

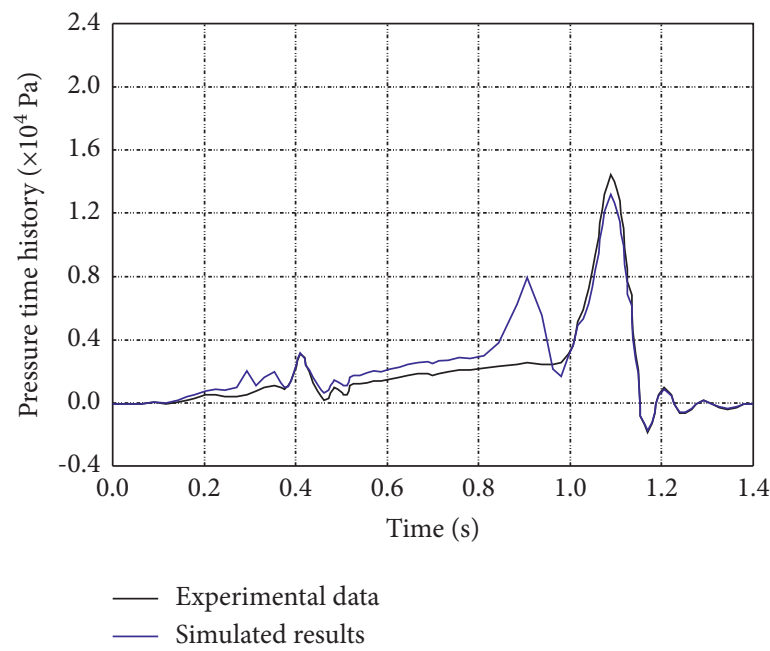

(e)

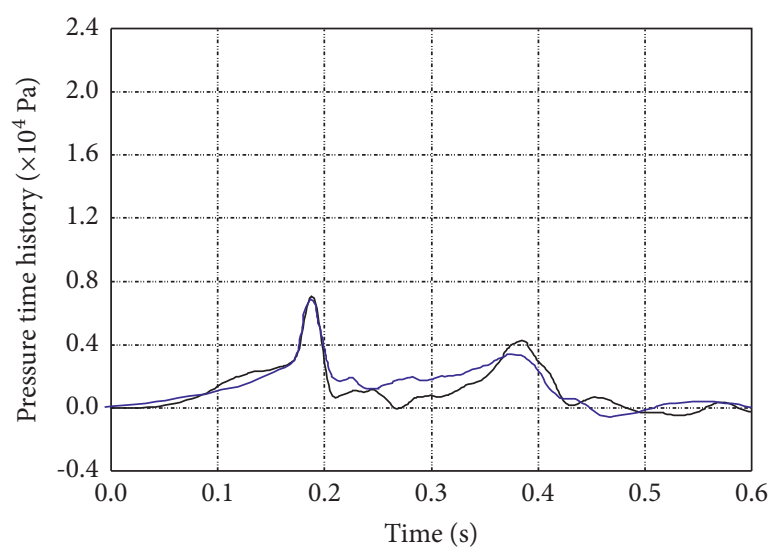

_ Experimental data

— Simulated results

(b)

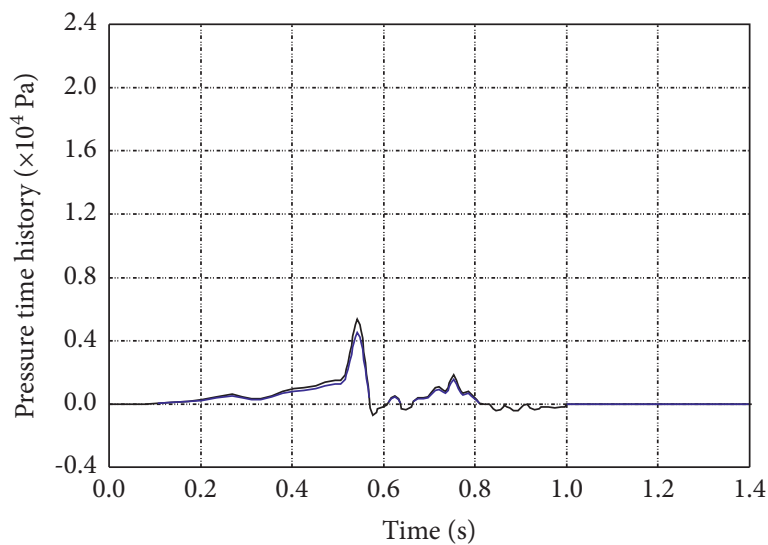

— Experimental data

_ Simulated results

(d)

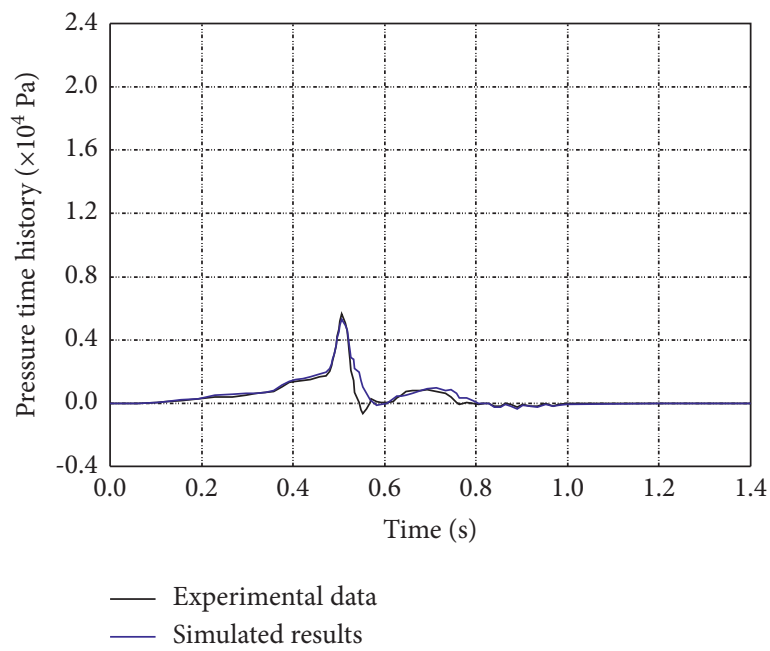

(f)

FIGURE 3: Pressure time histories from experimental data and simulated results. (a) Chamber I with a $2.7 \mathrm{~m}^{2}$ vent (Hydrogen): IP1 (b) Chamber II with a $5.4 \mathrm{~m}^{2}$ vent (Hydrogen): IP2. (c) Chamber I with a $2.7 \mathrm{~m}^{2}$ vent (Methane): IP1 (d) Chamber II with a $5.4 \mathrm{~m}^{2}$ vent (Methane): IP2. (e) Chamber I with a $2.7 \mathrm{~m}^{2}$ vent (Propane): IP1 (f) Chamber II with a $5.4 \mathrm{~m}^{2}$ vent (Propane): IP2. 


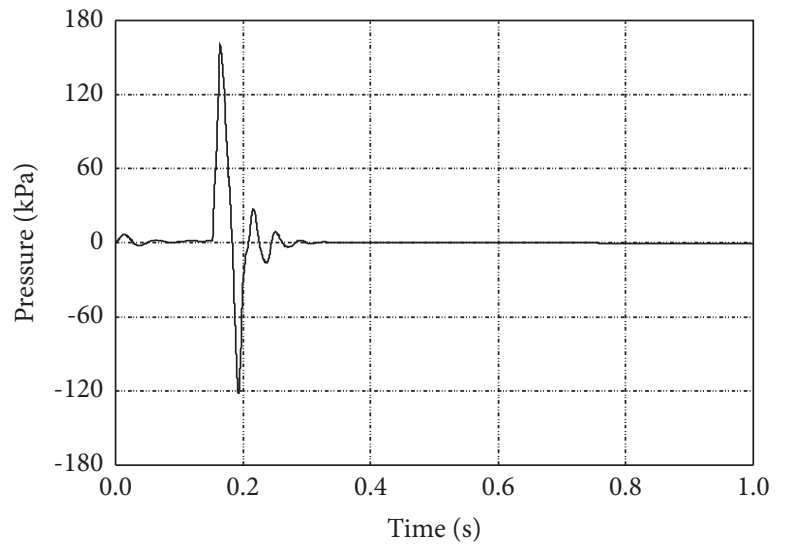

(a)

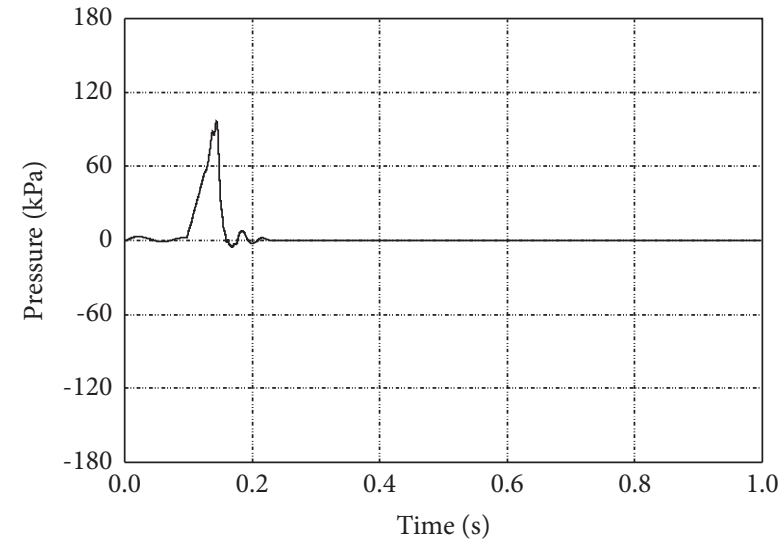

(b)

FIgURE 4: Pressure time history of the blast shock wave. (a) Scheme 1. (b) Scheme 2

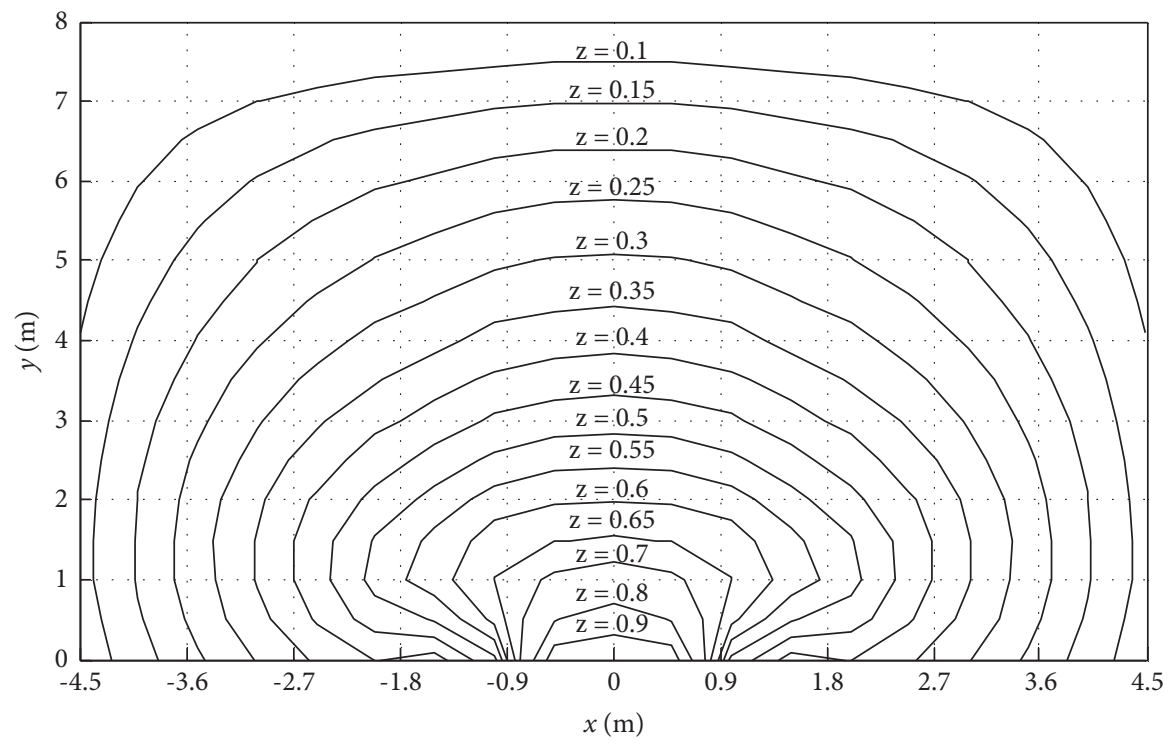

(a)

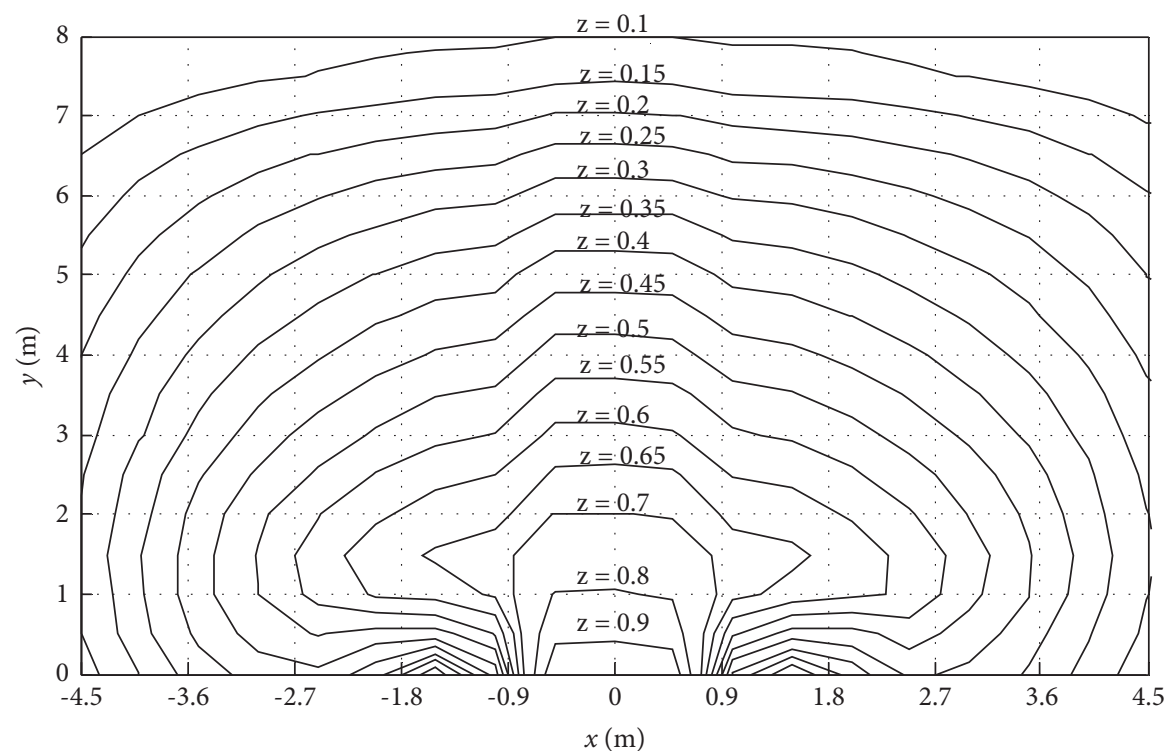

(b)

Figure 5: Peak pressure space distributions of Schemes 1 and 2. (a) Scheme 1. (b) Scheme 2 


\section{Parametric studies}

Different from explosive charge explosion, the shock wave of gas explosion is easily affected by the surrounding environment, such as initial conditions (initial temperature $[34,35]$ and gas volume concentration [34-36]) and kitchen parameters (width, length, height, opening, and buffer) $[37,38]$. Therefore, it is necessary to have a deep understanding of these interfering factors.

5.1. Initial condition. In the section, a series of finite element analyses are conducted on the premixed methane/air mixture explosion in the kitchen to investigate the influence of the initial temperature and gas volume concentration on the peak pressure.

5.1.1. Initial temperature. Figure 6 illustrates the relation between $p_{i c}$ and $T$ under different initial gas volume concentration environments, where $p_{i c}$ is the peak pressure considering the initial condition and $T$ is the initial temperature.

According to the basic theory of combustion, the higher the initial temperature is, the higher the gas combustion reaction rate becomes. However, the gas is expelled from the kitchen with the increase in the initial temperature, and the corresponding total mass of the gas in the kitchen is smaller at higher initial temperature. It can be observed from figure 6 that the peak pressure is mainly determined by the latter. Therefore, the peak pressure decreases gradually as the initial temperature increases.

5.1.2. Initial gas volume concentration. Figure 7 describes the relation between $p_{i c}$ and $C$ under different initial temperature environments, where $p_{i c}$ is the peak pressure in consideration of the initial condition and $C$ is the initial gas volume concentration.

The gas complete combustion occurs at the lower initial gas volume concentration, and directly determines the peak pressure. Nevertheless, the gas incomplete combustion occurs at higher initial gas volume concentration. The main reason for this is the limited oxygen volume concentration, which governs the peak pressure in such case. Hence, with the increase in the initial gas volume concentration, the peak pressure first increases and reaches a maximum, then decreases gradually. Additionally, the initial gas volume concentration corresponding to the highest pressure is close to the stoichiometric volume concentration [39] which is about $10 \%$.

Figure 8 depicts the relation among $\gamma_{i c}, T$ and $C$, where $\gamma_{i c}$ is the influence coefficient of the initial condition, $T$ is the initial temperature and $C$ is the initial gas volume concentration. The initial temperature has an important influence on the gas detonation parameters [40]. The upper explosion limit of the gas increases but the lower explosion limit of the gas decreases as the initial temperature increases. Consequently, there is a significant influence on the peak pressure by the coupled interaction between the initial temperature and the initial gas volume concentration, especially at the upper and lower explosion limits of the gas [41].

In view of the relevant researches and the results from finite element analyses of this study, an empirical relation among $\gamma_{i c}$, $T$ and $C$ can be obtained through the nonlinear regression and expressed as equation (10). It can be seen from Figures 6-8 that the results predicted by (10) coincide very well with the numerical simulation results.

The influence coefficient of the initial condition can be gained by dividing $p_{i c}$ by $p_{O p}$. Thus, the difference in the kitchen design layout is eliminated. The corresponding suggested equation can be expressed as follows:

$$
\begin{aligned}
\gamma_{i c}= & \frac{p_{i c}}{p_{O p}} \\
= & \left(3.56 \times 10^{-5} T-0.0356\right) \\
& \cdot\left[10000 C^{2}-1980 C+4.44 \times 10^{-2} T+84.52\right]+0.57 .
\end{aligned}
$$

5.2. Kitchen parameter. In order to explore the influence of the kitchen on the peak pressure, a range of numerical simulation analyses are conducted on the kitchens of different sizes, openings, and buffers. All the parameters under consideration are illustrated as follow: kitchen width $w$ from 1.20 to $4.80 \mathrm{~m}$; kitchen length $l_{1}$ from 1.20 to $4.80 \mathrm{~m}$; kitchen height $h$ from 2.40 to $6.00 \mathrm{~m}$; wall hole ratio $\lambda$ from 0.00 to 0.60 ; and buffer length $l_{2}$ from 1.20 to $4.80 \mathrm{~m}$. The relation between $p_{k}$ and kitchen parameters is displayed in figure 9 , where $p_{k}$ is the peak pressure with taking into account the kitchen.

5.2.1. Width, length, and height. It can be observed from Figures 9(a)-9(c) that the peak pressure increases slowly but linearly with the increase in the width, length, and height. Furthermore, the width, length, and height of kitchen enhance the peak pressure in different extents [42]. Because of the gravity effect, the height show slightly significant effect than other parameters.

5.2.2. Opening. Once there is a gas explosion in the kitchen, the glasses in the window is easy to be destroyed. The window opening just plays the role of pressure relief and releases a large amount of explosive energy quickly, greatly reducing the peak pressure [43]. It can be seen from Figure 9(d) that the peak pressure decreases significantly with increase in the hole ratio of the wall.

5.2.3. Buffer. If a gas explosion occurs in the kitchen, first of all, the blast shock wave first gets into the buffer zone, and then it continues to propagate in a building. Consequently, the buffer zone plays the buffer role and reduces the peak pressure [44]. It can be found from Figure 9(e) that the longer the length of the buffer is, the smaller the peak pressure becomes. 

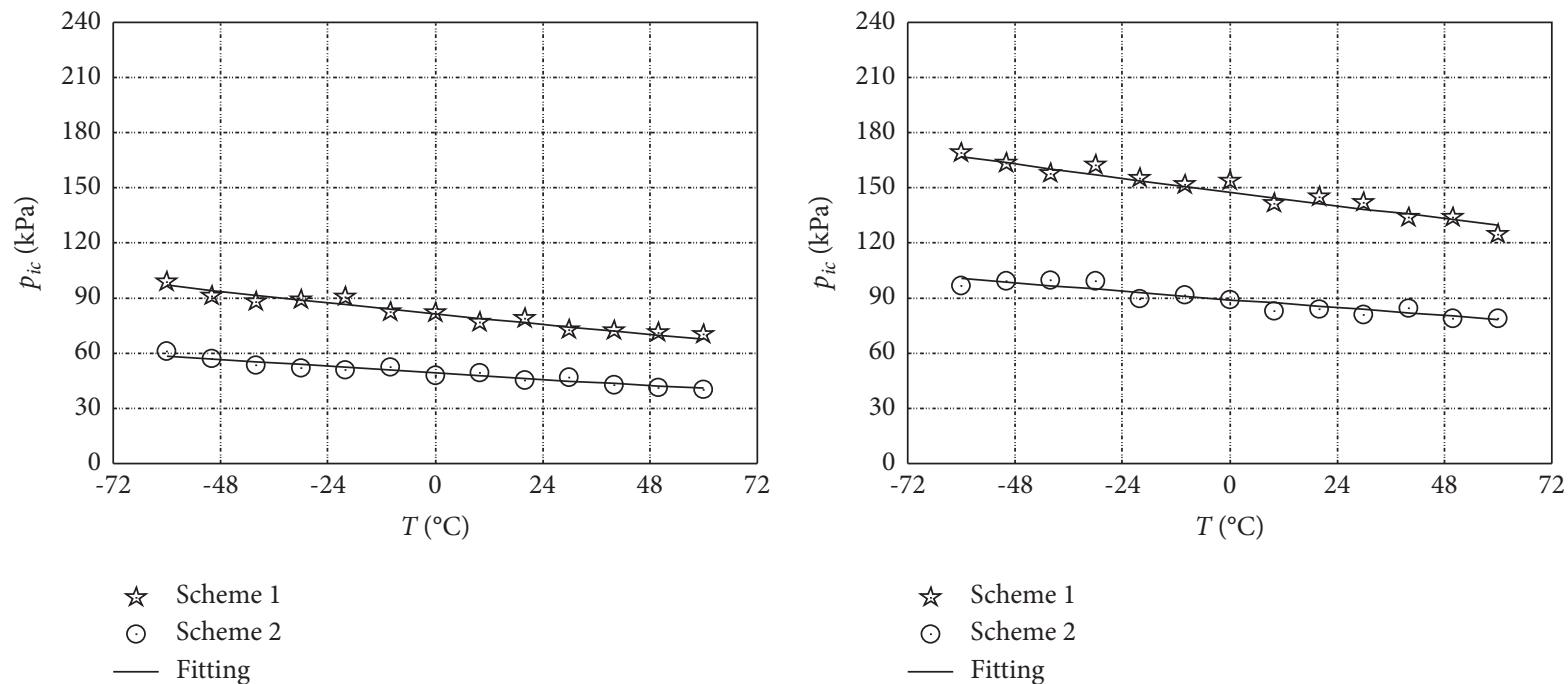

(a)

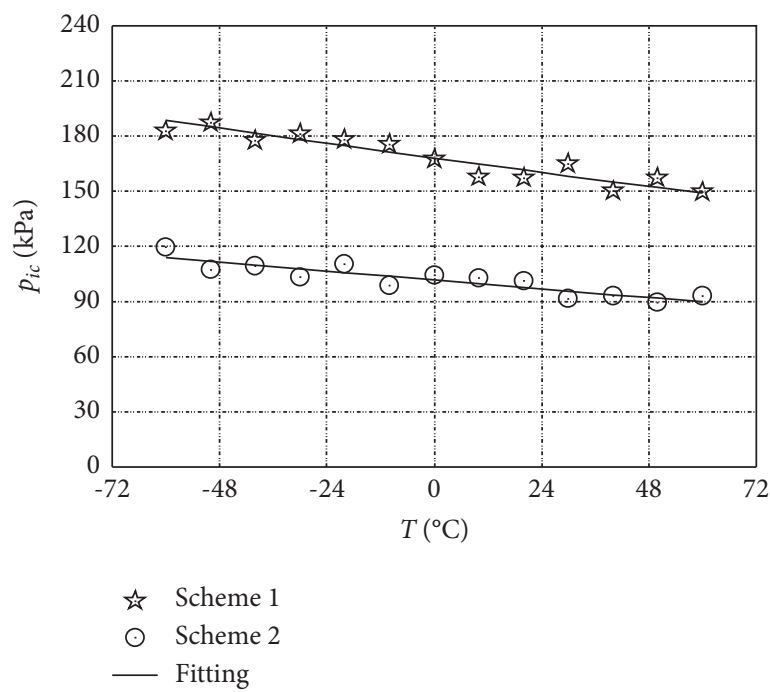

(c)

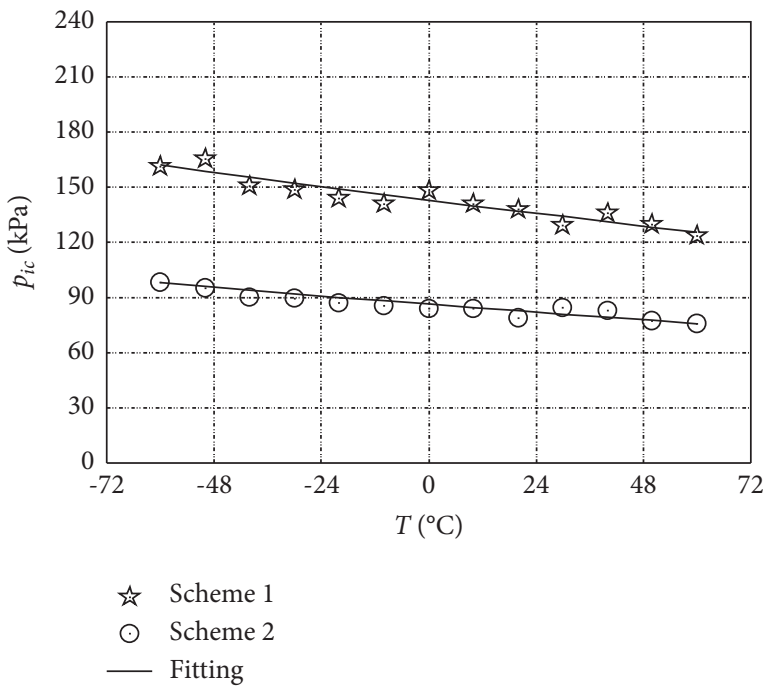

(d)

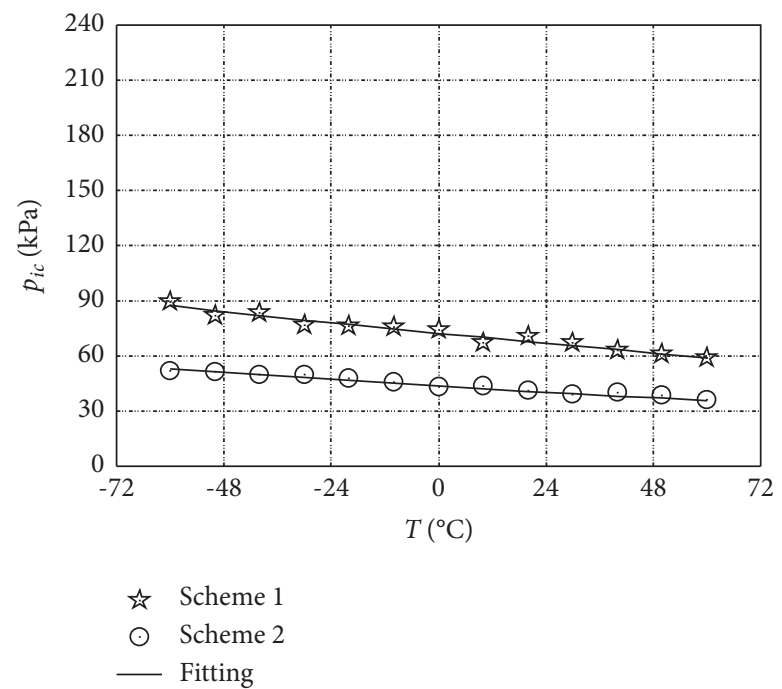

(e)

Figure 6: Relation between $(\mathrm{p})_{i c}$ and $(\mathrm{T})$ under different initial gas volume concentration environments. $(\mathrm{a})(\mathrm{C})=6 \%(\mathrm{~b})(\mathrm{C})=8 \%$. (c) $(\mathrm{C})=10 \%(\mathrm{~d})(\mathrm{C})=12 \%$. (e) $(\mathrm{C})=14 \%$. 


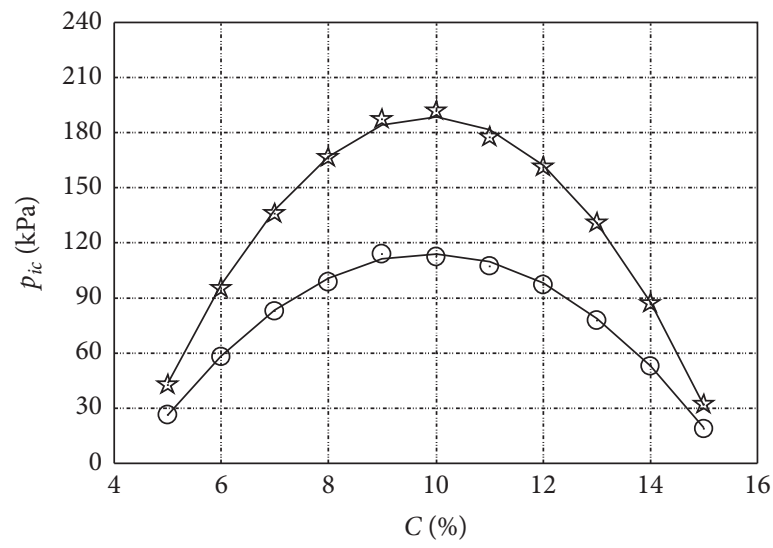

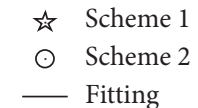

Fitting

(a)

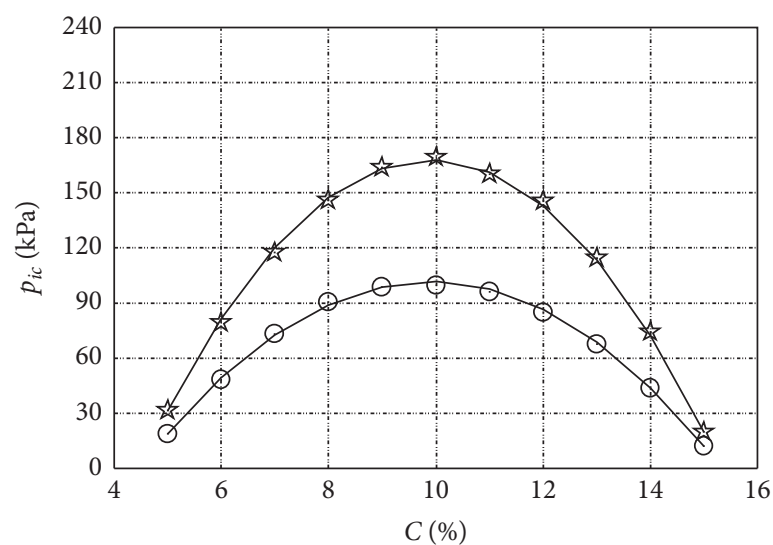

th Scheme 1

$\odot$ Scheme 2

— Fitting

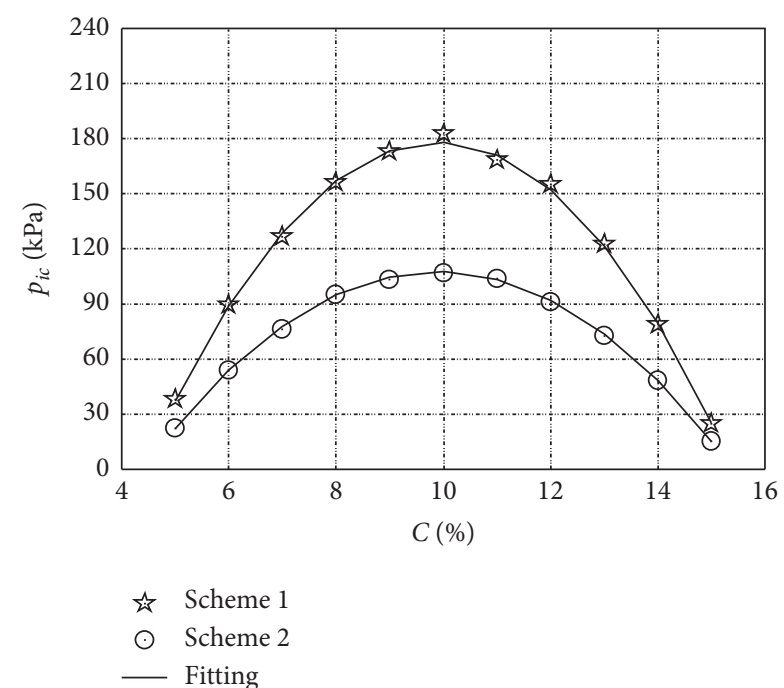

(b)

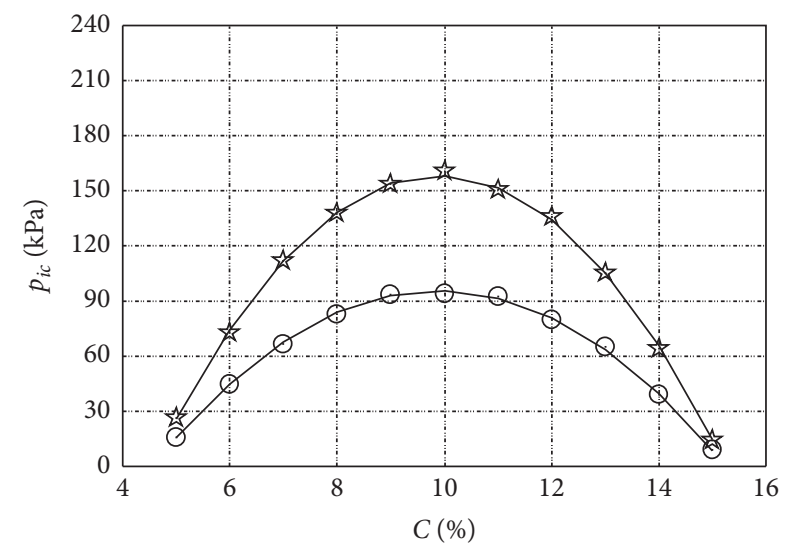

Scheme 1

$\odot$ Scheme 2

- Fitting

(c)

(d)

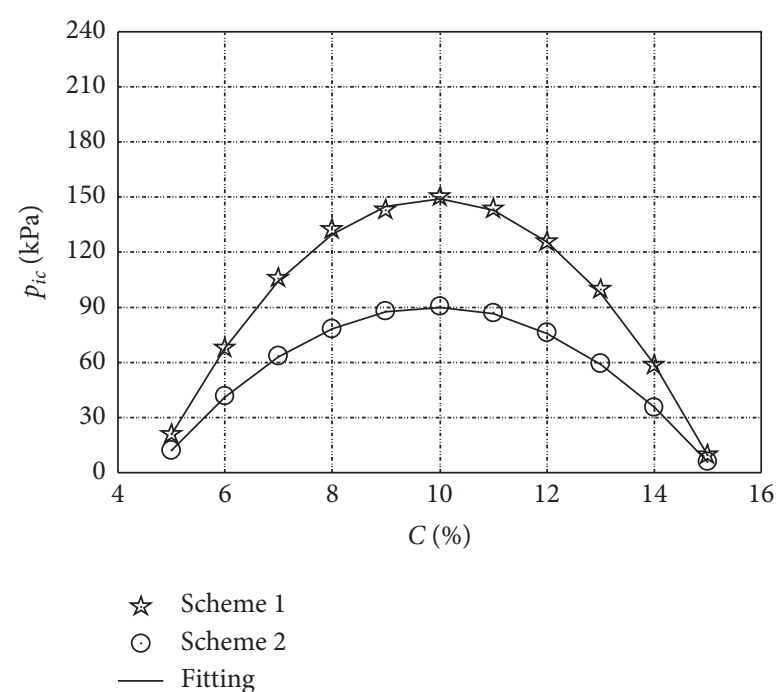

(e)

Figure 7: Relation between $(\mathrm{p})_{i c}$ and $(\mathrm{C})$ under different initial temperature environments. $(\mathrm{a})(\mathrm{T})=-60{ }^{\circ} \mathrm{C}(\mathrm{b})(\mathrm{T})=-30{ }^{\circ} \mathrm{C}$. $(\mathrm{c})(\mathrm{T})=+0{ }^{\circ} \mathrm{C}$ (d) $(\mathrm{T})=+30{ }^{\circ} \mathrm{C}$. (e) $(\mathrm{T})=+60{ }^{\circ} \mathrm{C}$. 


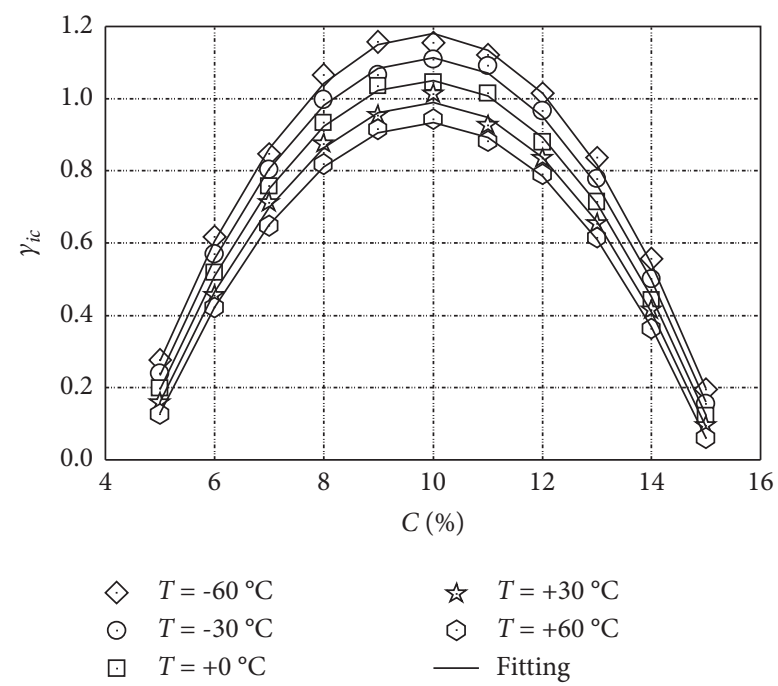

FIgURE 8: Relation among $\gamma_{i c}$, (T) and (C).
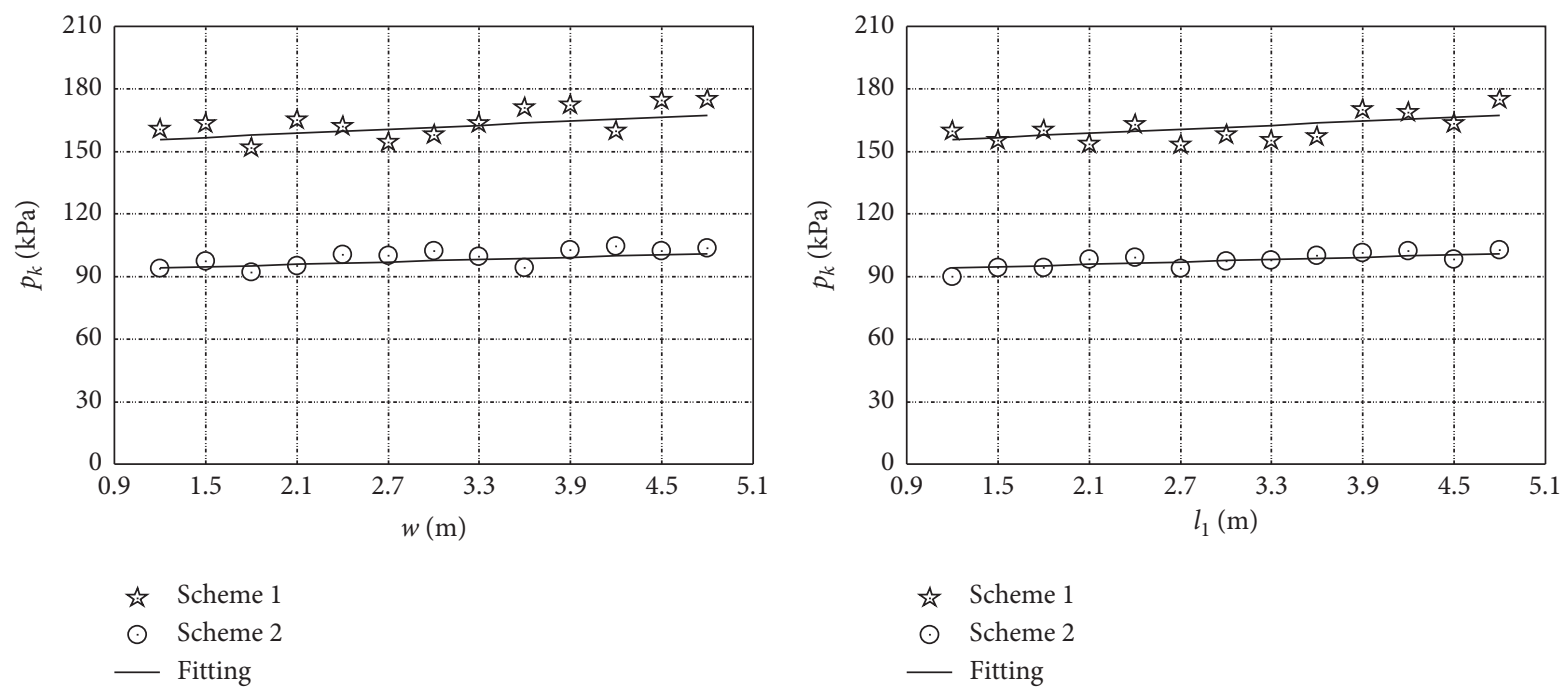

(a)
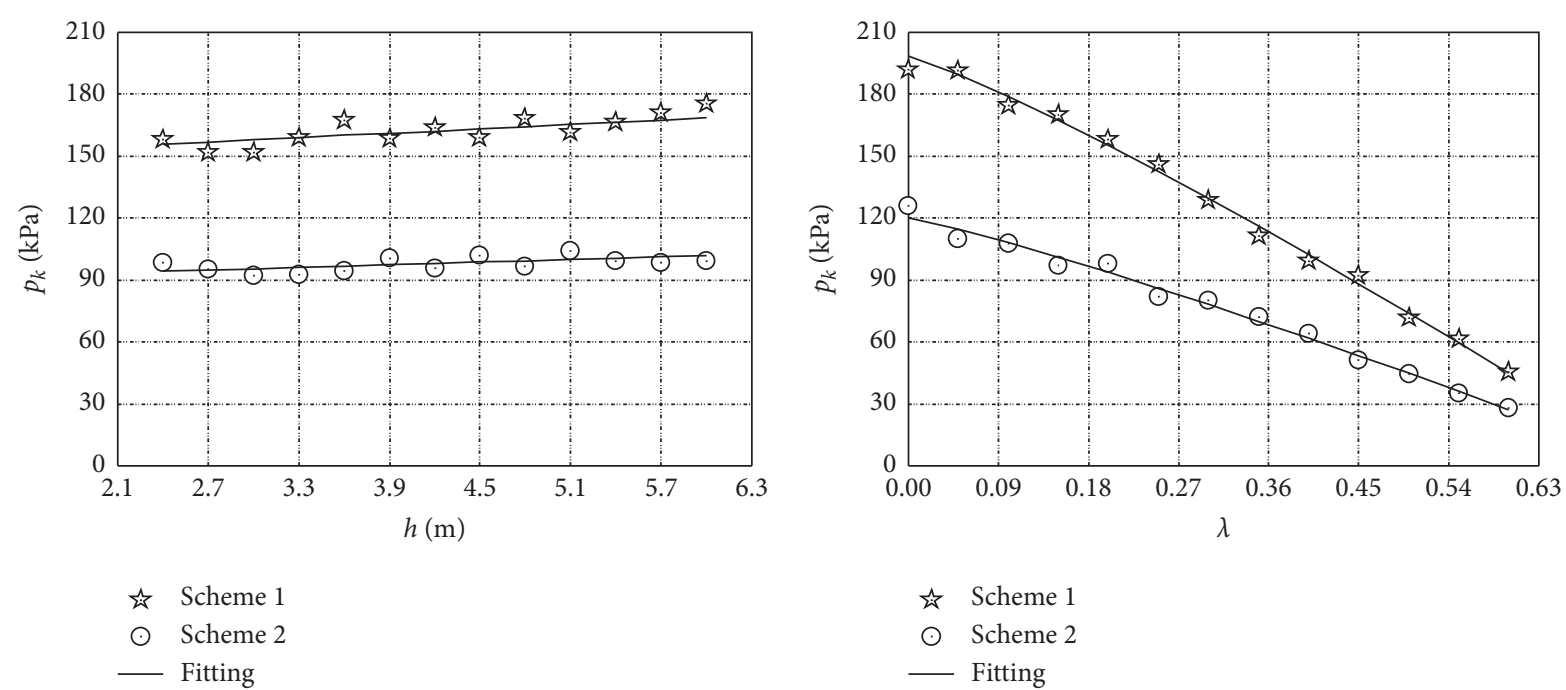

(c)

(d)

FIgUre 9: Continued. 


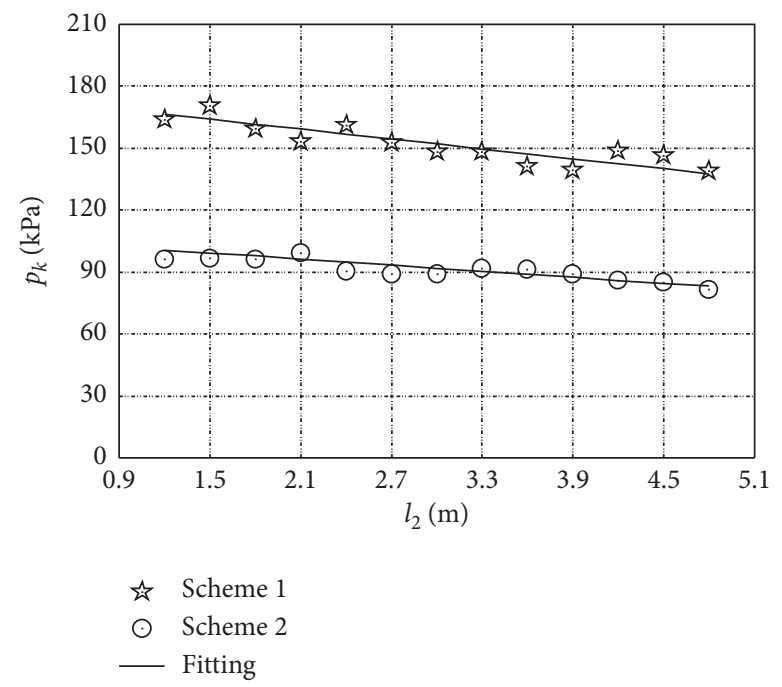

(e)

Figure 9: Relation between (p) and kitchen parameters. (a) Width. (b) Length. (c) Height. (d) Opening. (e) Buffer.

To sum up, the peak pressure varies significantly with the opening and the buffer. However, it has little relation with the width, length, and height of kitchen.

From the associated documents and the numerical simulation results in the present study, an empirical relation between $\gamma_{k}$ and kitchen parameters can be gained through the nonlinear fitting by using the ordinary least square method and expressed as (11). It can be seen from Figure 9 that the fitting results are in good accordance with the simulated results, regardless of any kitchen parameter.

The influence coefficient of the kitchen can be gained by dividing $p_{k}$ by $p_{O p}$. Thus, the difference in the kitchen design layout is eliminated. It can be given by:

$$
\begin{aligned}
\gamma_{k}= & \frac{p_{k}}{p_{O p}}=0.05\left(\frac{w}{w_{k}}+\frac{l_{1}}{l_{k}}\right)+0.08 \frac{h}{h_{k}} \\
& -0.24\left(\frac{\lambda}{\lambda_{k}}\right)^{1.15}-0.10 \frac{l_{2}}{l_{b}}+1.16 .
\end{aligned}
$$

\section{Proposed method to predict the properties of the blast shock wave}

6.1. Basic step of the proposed method. Through the analysis and the research on the gas explosion inside the building, a new method is proposed herein to predict the peak pressure of the blast shock wave. The flow chart is depicted in Figure 10 below, and its basic steps are as follows:

(1) Give the basic information that needed in this study, such as gas type, initial conditions (initial temperature and gas volume concentration) and kitchen parameters (width, length, height, opening, and buffer). If not the methane gas, the equivalent mass can be calculated according to equation (12), and the corresponding initial gas volume concentration is also obtained. Repeat steps (2) through (4).
The equivalent mass of other gas can be defined as follows:

$$
m_{E q}=\frac{E_{\text {Other }}}{E_{\text {Methane }}} m_{\text {Other }}
$$

where $E_{\text {Methane }}$ and $E_{\text {Other }}$ are the initial internal energy of methane and other gas, respectively; $m_{\text {Other }}$ is the mass of other gas.

(2) The two influence coefficients $\gamma_{i c}$ and $\gamma_{k}$ can be obtained according to equations (10) and (11), respectively. Thus, the maximum pressure considering the initial conditions and the kitchen parameters is $\gamma_{i c} \gamma_{k} p_{O p}$.

(3) The peak pressure of the explosion shock wave is not uniformly distributed in the building, and it is needed to calculate the peak pressure at any position. Calculate it based on Figures 5(a) and (b).

(4) If the blast shock wave spreads to the wall, the pressure increases immediately and generates a reflective highpressure zone near the blast side. Use equation (13). Henrych [45] derived an empirical relation between the peak pressures of the reflected and incident wave. It can be expressed as follows:

$$
\frac{p_{r}}{p_{i}}=\frac{8 p_{i}+14}{p_{i}+7.2}, \quad p_{i} \leq 4 \mathrm{MPa}
$$

where $p_{r}$ and $p_{i}$ are the peak pressures of the reflected and incident wave, respectively.

(5) Draw the peak pressure nephogram under different working conditions.

The calculation formulas used in the proposed method are based on the previous researches and the numerical 


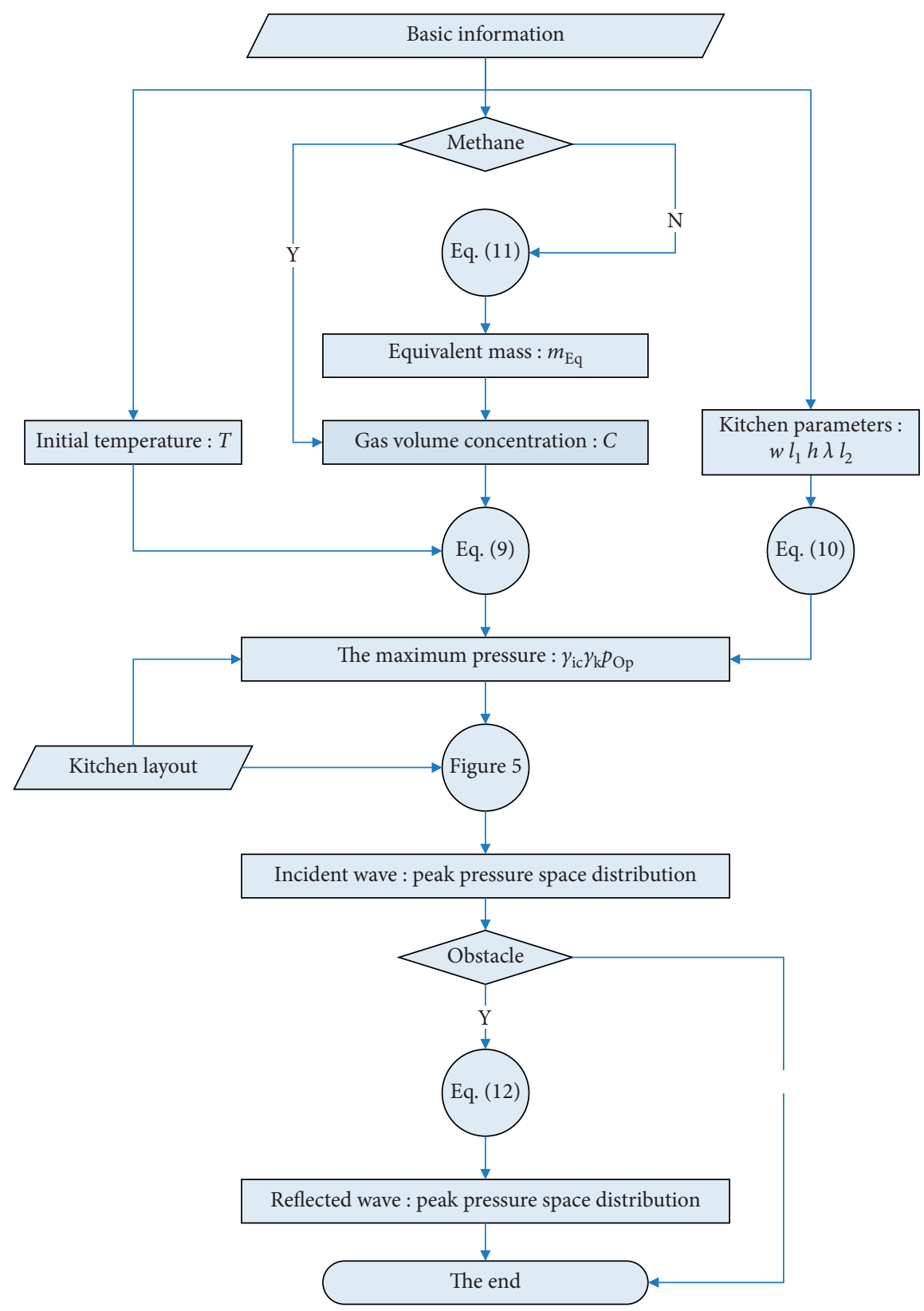

FIgURE 10: Flow chart of the proposed method.

simulation results. The analysis procedure is comprehensive whilst the results are reliable. Furthermore, it indicates that the proposed method can accurately and effectively predict the peak pressure of the blast shock wave inside the building.

6.2. Example study. In order to estimate the killing power of the explosion shock wave accurately, it is urgent to present some quantitative killing criterions, such as the pressure, the impulse and the combination of the above two. The U.S. military standard [7] specifies the pressure criterion of $45.7 \mathrm{kPa}$ for eardrum rupture with a probability of $10 \%$ and $103.4 \mathrm{kPa}$ in the duration of $50 \mathrm{~ms}$ for lung damage. Using the above two kitchens as the examples, the propagation processes of the gas explosion are simulated using the CFD analysis software OpenFOAM to analyze the space distribution of the blast shock wave.

The peak pressure nephograms under different working conditions: Schemes 1 and 2 are illustrated Figures 11 and 12, respectively. The lower the initial temperature is, the higher the peak pressure is. The peak pressure first increases and then decreases gradually with the increase in the initial gas volume concentration. Additionally, the kitchen design layout seriously affects the peak pressure.

In terms of the peak pressure space distribution of the explosion shock wave, the peak pressure is much higher than the threshold of the killing pressure which is unsafe for the humans in the building. 

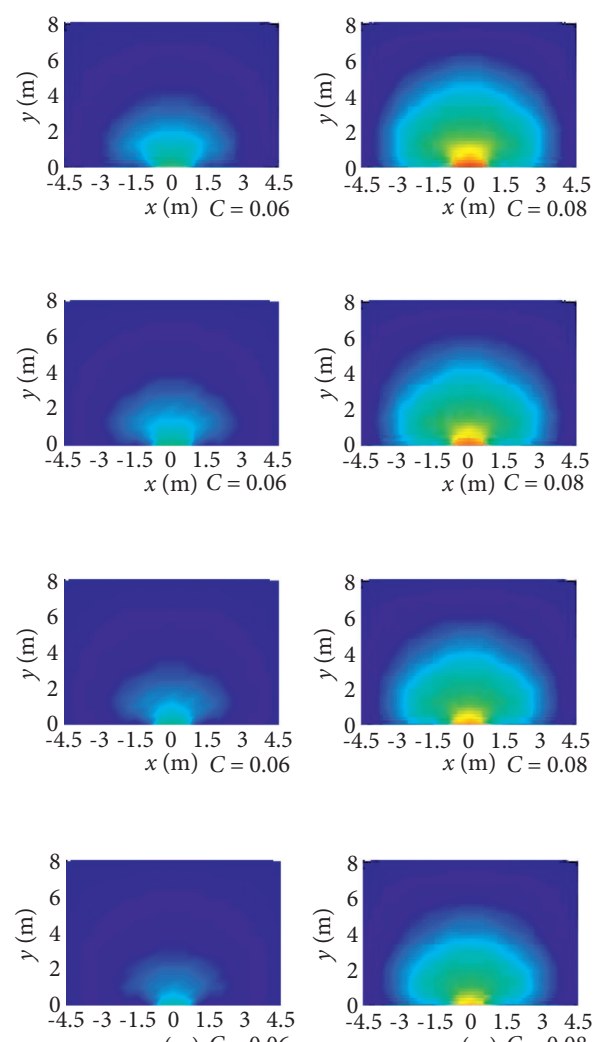

$x(\mathrm{~m}) \mathrm{C}=0.06$
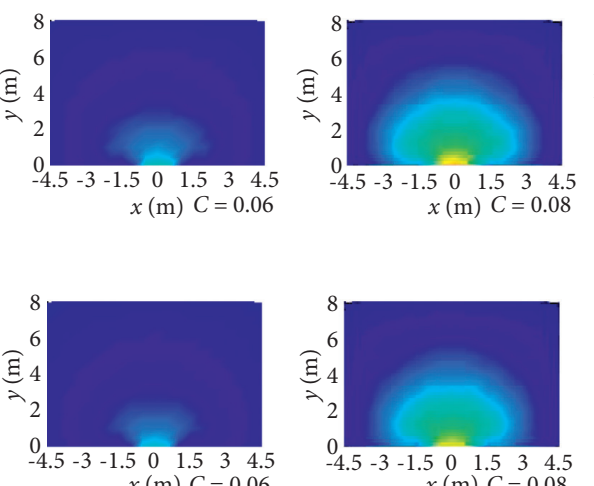

$x(\mathrm{~m}) C=0.06$
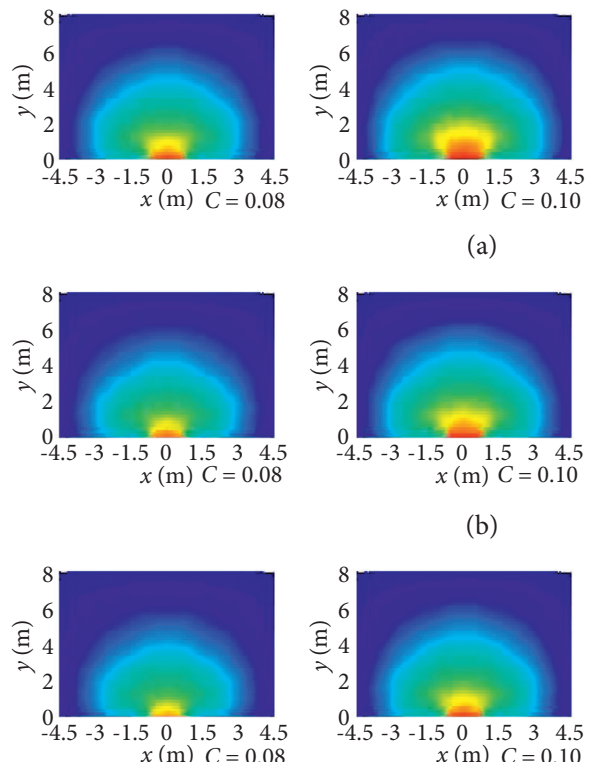

(a)

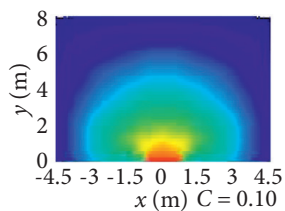

(b)

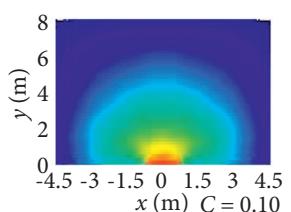

(c)

(d)
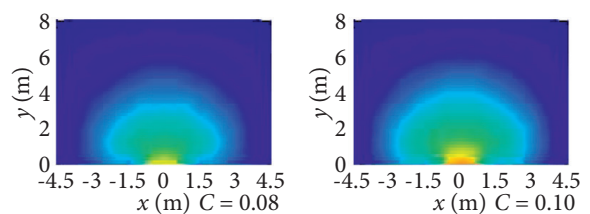
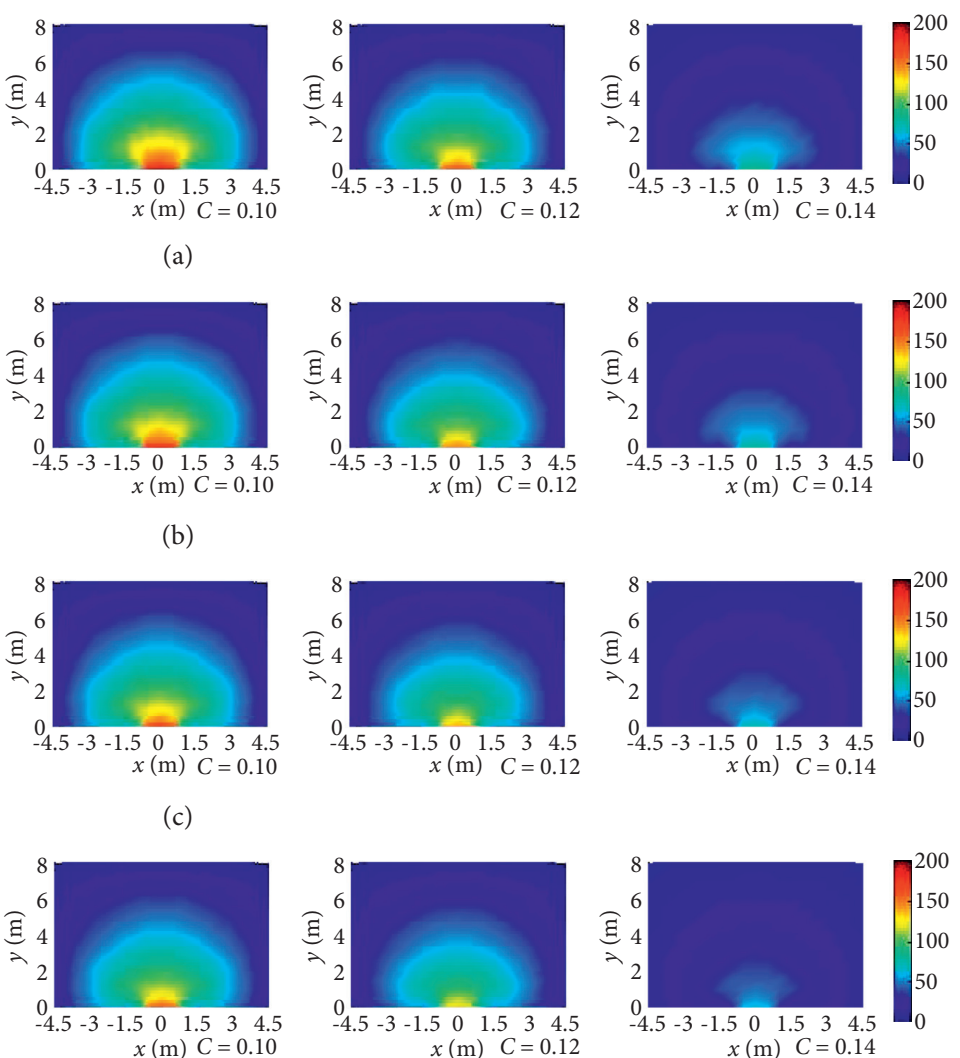

$x(\mathrm{~m}) \mathrm{C}=0.14$
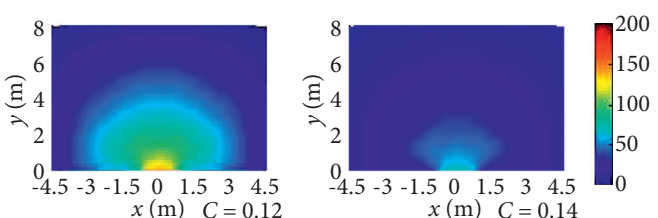

$x(\mathrm{~m}) \quad C=0.14$
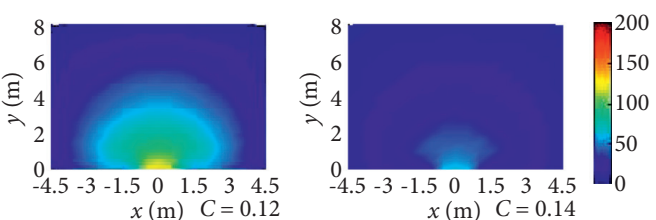

$x(\mathrm{~m}) \quad C=0.14$
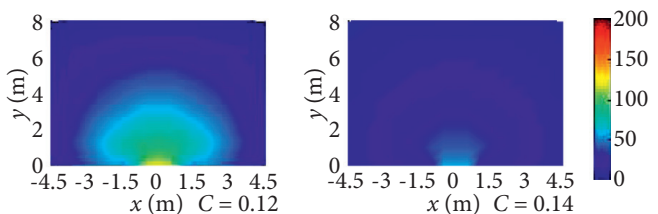

(e)

Figure 11: Peak pressure nephograms under different working conditions: Scheme $1(\mathrm{kPa}) .(\mathrm{a})(\mathrm{T})=-60{ }^{\circ} \mathrm{C} .(\mathrm{b})(\mathrm{T})=-30{ }^{\circ} \mathrm{C} .(\mathrm{c})(\mathrm{T})=$ $+0{ }^{\circ} \mathrm{C}$. (d) $(\mathrm{T})=+30{ }^{\circ} \mathrm{C}$. (e) $(\mathrm{T})=+60{ }^{\circ} \mathrm{C}$.
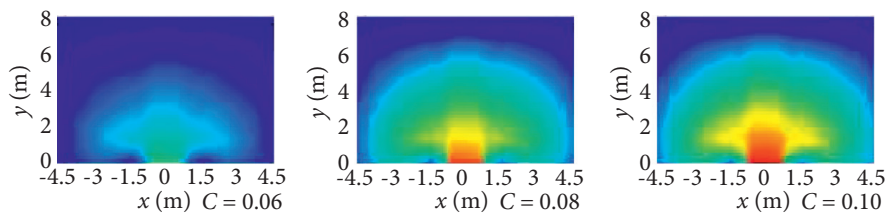

(a)
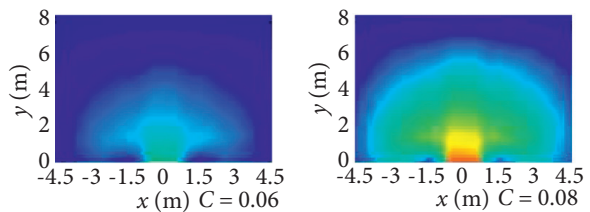
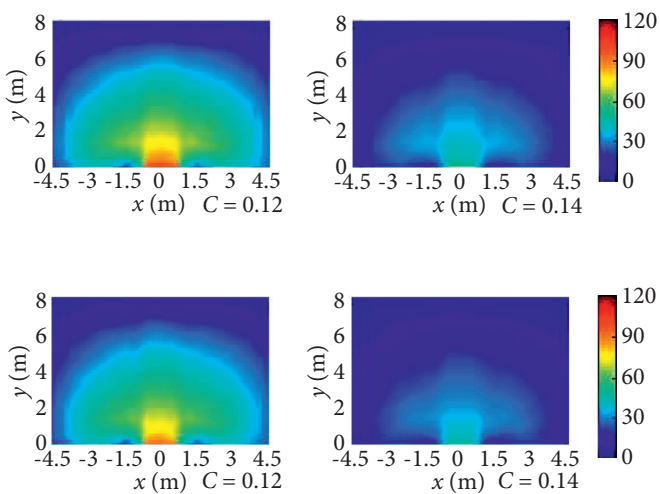

(b)

Figure 12: Continued. 

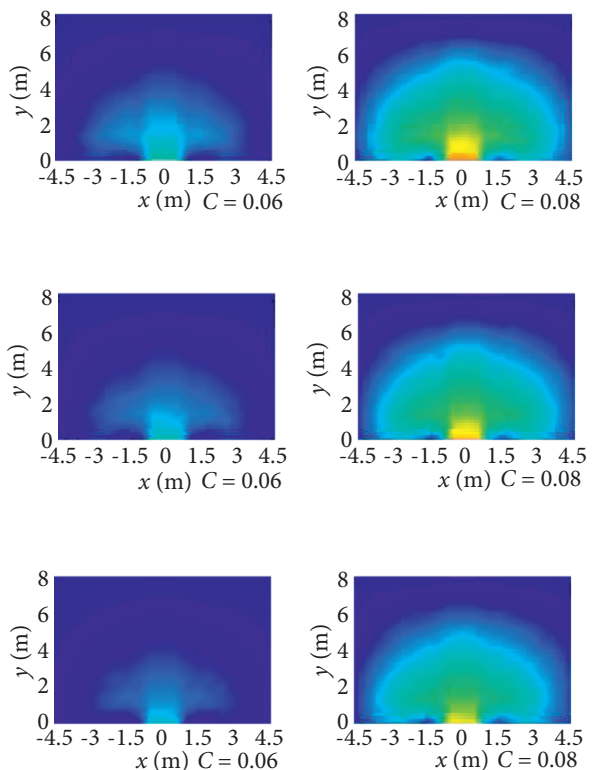
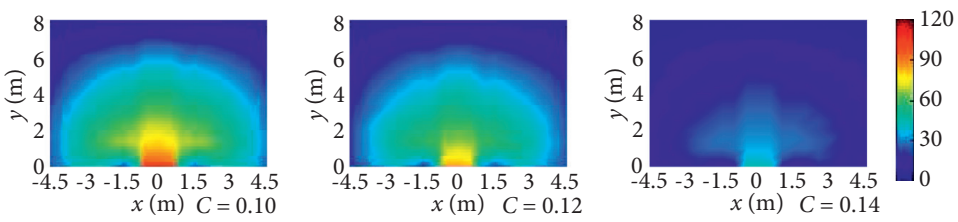

(c)
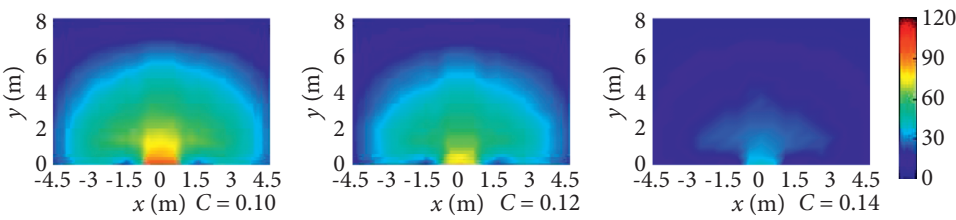

(d)
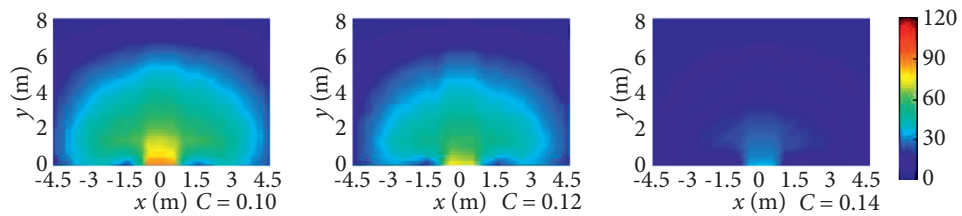

(e)

Figure 12: Peak pressure nephograms under different working conditions: Scheme $2(\mathrm{kPa}) .(\mathrm{a})(\mathrm{T})=-60{ }^{\circ} \mathrm{C} .(\mathrm{b})(\mathrm{T})=-30{ }^{\circ} \mathrm{C} .(\mathrm{c})(\mathrm{T})=$ $+0{ }^{\circ} \mathrm{C}$. (d) $(\mathrm{T})=+30{ }^{\circ} \mathrm{C}$. (e) $(\mathrm{T})=+60{ }^{\circ} \mathrm{C}$.

\section{Conclusion}

In this research, a new method has been developed herein to predict the peak pressure of the blast shock wave of a gas explosion inside a building. A series of numerical simulation analyses are conducted on this problem. From the research results of this present study, the main conclusions are drawn as follows:

(1) The pressure time history and the peak pressure space distribution are greatly influenced by the kitchen design layout. There is a significant influence on the peak pressure by the coupled interaction between the initial temperature and the initial gas volume concentration, especially at the upper and lower explosion limits of the gas.

(2) The peak pressure varies significantly with the opening and the buffer. However, it has little relation with the width, length, and height of the kitchen. The proposed method can accurately and effectively predict the peak pressure of the blast shock wave inside the building.

(3) In terms of the peak pressure space distribution of the explosion shock wave, the peak pressure is much higher than the threshold of the killing pressure, which is unsafe for the humans in the building.

\section{Data Availability}

The simulation data used to support the findings of this study are included within the article.

\section{Conflicts of Interest}

The authors declare that they have no conflicts of interest.

\section{Acknowledgments}

The authors would like to gratefully acknowledge the financial support provided by the Key Research and Development (R\&D) Program of Tangshan [No. 19150232E], National Natural Science Foundation of China [NO. 51908085], Natural Science Foundation of Chongqing [cstc2020jcyj-msxmX0010], Fundamental Research Funds for the Central Universities [2020CDJ-LHZZ-013], The Youth Innovation Team of Shaanxi Universities [21JP138] and Key Research and Development Program of Shaanxi [2021SF-521].

\section{References}

[1] J. Pospíśil, P. Charvát, O. Arsenyeva, L. Klimeš, M. Špiláček, and J. J. Klemeš, "Energy demand of liquefaction and regasification of natural gas and the potential of LNG for operative thermal energy storage," Renewable and Sustainable Energy Reviews, vol. 99, pp. 1-15, 2019.

[2] E. Strantzali, K. Aravossis, G. A. Livanos, and C. Nikoloudis, "A decision support approach for evaluating liquefied natural gas supply options: implementation on Greek case study," Journal of Cleaner Production, vol. 222, pp. 414-423, 2019.

[3] J. Weerheijm, J. Verreault, and M. M. Van Der Voort, "Quantitative risk analysis of gas explosions in tunnels," Fire Safety Journal, vol. 97, pp. 146-158, 2018.

[4] X. Meng, Q. Liu, X. Luo, and X. Zhou, "Risk assessment of the unsafe behaviours of humans in fatal gas explosion accidents in China's underground coal mines," Journal of Cleaner Production, vol. 210, pp. 970-976, 2019.

[5] T. Chyży and M. Mackiewicz, "Simplified function of indoor gas explosion in residential buildings," Fire Safety Journal, vol. 87, pp. 1-9, 2017. 
[6] AASTP-1, Manual of NATO Safety Principles for the Storage of Military Ammunition and Explosives, North Atlantic Treaty Organization, Brussels, Belgium, 2006.

[7] DoD 6055.9-STD, DoD Ammunition and Explosive Safety Standards, Departments of Defense, Arlington, VA, USA, 2008.

[8] J. Henrych, The Dynamics of Explosion and its Use, Elsevier Scientific Publishing Company, Amsterdam, Netherlands, 1979.

[9] ОРЛЕНКО ЛШ. физика взрыва. ФИЗМАТЛИТ, Moscow, Russia, 2002.

[10] O. Pennetier, M. William-Louis, and A. Langlet, "Numerical and reduced-scale experimental investigation of blast wave shape in underground transportation infrastructure," Process Safety and Environmental Protection, vol. 94, pp. 96-104, 2015.

[11] T. Ma, X. Xu, and J. Ning, "Research on propagation laws of explosion shock wave inside metro station," Journal of Loss Prevention in the Process Industries, vol. 46, pp. 54-68, 2017.

[12] I. E. Edri, V. R. Feldgun, Y. S. Karinski, and D. Z. Yankelevsky, "The blast load acting on a structure in an internal explosion scenario," Blast, Impact Loading, and Response; and Research and Education, ASCE Structures Congress, Reston, VA, USA, pp. 362-375, 2018.

[13] T. Ji, X. Qian, M. Yuan et al., "Case study of a natural gas explosion in Beijing, China," Journal of Loss Prevention in the Process Industries, vol. 49, pp. 401-410, 2017.

[14] D. Wang, X. Qian, M. Yuan, T. Ji, W. Xu, and S. Liu, "Numerical simulation analysis of explosion process and destructive effect by gas explosion accident in buildings," Journal of Loss Prevention in the Process Industries, vol. 49, pp. 215-227, 2017.

[15] K. Wang, T. Shi, Y. He, M. Li, and X. Qian, "Case analysis and CFD numerical study on gas explosion and damage processing caused by aging urban subsurface pipeline failures," Engineering Failure Analysis, vol. 97, pp. 201-219, 2019.

[16] J. Li and H. Hao, "Internal and external pressure prediction of vented gas explosion in large rooms by using analytical and CFD methods," Journal of Loss Prevention in the Process Industries, vol. 49, pp. 367-381, 2017.

[17] S. Kundu, J. Zanganeh, and B. Moghtaderi, "A review on understanding explosions from methane-air mixture," Journal of Loss Prevention in the Process Industries, vol. 40, pp. 507-523, 2016.

[18] S. Shi, B. Jiang, and X. Meng, "Assessment of gas and dust explosion in coal mines by means of fuzzy fault tree analysis," International Journal of Mining Science and Technology, vol. 28, no. 6, pp. 991-998, 2018.

[19] M. Nyström, "Kitchen design: energy and health in the eyes of the beholder," Energy for Sustainable Development, vol. 7, no. 3, pp. 8-29, 2003.

[20] O. Han, A. Li, and R. Kosonen, "Hood performance and capture efficiency of kitchens: a review," Building and Environment, vol. 161, Article ID 106221, 2019.

[21] C.-M. Chiang, C.-M. Lai, P.-C. Chou, and Y.-Y. Li, "The influence of an architectural design alternative (transoms) on indoor air environment in conventional kitchens in Taiwan," Building and Environment, vol. 35, no. 7, pp. 579-585, 2000.

[22] V. J. L. Gan, H. K. Wong, K. T. Tse, J. C. P. Cheng, I. M. C. Lo, and C. M. Chan, "Simulation-based evolutionary optimization for energy-efficient layout plan design of high-rise residential buildings," Journal of Cleaner Production, vol. 231, pp. 1375-1388, 2019.
[23] V. Bychkov, M. Modestov, and C. K. Law, "Combustion phenomena in modern physics: I. Inertial confinement fusion," Progress in Energy and Combustion Science, vol. 47, pp. 32-59, 2015.

[24] ANSYS, ANSYS Help, ANSYS Corporation, Canonsburg, PA, USA, 2019.

[25] T. Poinsot and D. Veynante, Theoretical and Numerical Combustion, R T Edwards, Inc., Philadelphia, PA, USA, 2001.

[26] B. E. Launder and D. B. Spalding, "The numerical computation of turbulent flows," Computer Methods in Applied Mechanics and Engineering, vol. 3, no. 2, pp. 269-289, 1974.

[27] R. D. Cowan and W. Fickett, "Calculation of the detonation properties of solid explosives with the kistiakowsky-wilson equation of state," The Journal of Chemical Physics, vol. 24, no. 5, pp. 932-939, 1956.

[28] ANSYS, AUTODYN Theory Manual, ANSYS Corporation, Canonsburg, PA, USA, 2019.

[29] R. I. Issa, "Solution of the implicitly discretised fluid flow equations by operator-splitting," Journal of Computational Physics, vol. 62, pp. 40-65, 1985.

[30] OpenFOAM, OpenFOAM User's Guide, CFD Direct \& The OpenFOAM Foundation, London, UK, 2020.

[31] C. R. Bauwens, J. Chaffee, and S. B. Dorofeev, "Vented explosion overpressures from combustion of hydrogen and hydrocarbon mixtures," International Journal of Hydrogen Energy, vol. 36, no. 3, pp. 2329-2336, 2011.

[32] O. Ram, E. Nof, and O. Sadot, "Dependence of the blast load penetrating into a structure on initial conditions and internal geometry," Experimental Thermal and Fluid Science, vol. 78, pp. 65-74, 2016.

[33] T. A. Rose and P. D. Smith, "Influence of the principal geometrical parameters of straight city streets on positive and negative phase blast wave impulses," International Journal of Impact Engineering, vol. 27, no. 4, pp. 359-376, 2002.

[34] A. M. Remennikov and T. A. Rose, "Modelling blast loads on buildings in complex city geometries," Computers \& Structures, vol. 83, no. 27, pp. 2197-2205, 2005.

[35] Y. Z. Li, H. T. Su, H. J. Ji, and W. Y. Cheng, "Numerical simulation to determine the gas explosion risk in longwall goaf areas: a case study of Xutuan Colliery," International Journal of Mining Science and Technology, vol. 1, pp. 1-8, 2020.

[36] C. Guo, H. Shao, S. Jiang, Y. Wang, K. Wang, and Z. Wu, "Effect of low-concentration coal dust on gas explosion propagation law," Powder Technology, vol. 367, pp. 243-252, 2020.

[37] Q. Zhang, L. Pang, and H. M. Liang, "Effect of scale on the explosion of methane in air and its shockwave," Journal of Loss Prevention in the Process Industries, vol. 24, no. 1, pp. 43-48, 2011.

[38] M. Mitu, M. Prodan, V. Giurcan, D. Razus, and D. Oancea, "Influence of inert gas addition on propagation indices of methane-air deflagrations," Process Safety and Environmental Protection, vol. 102, pp. 513-522, 2016.

[39] B. Vanderstraeten, D. Tuerlinckx, J. Berghmans, S. Vliegen, E. Van't Oost, and B. Smit, "Experimental study of the pressure and temperature dependence on the upper flammability limit of methane/air mixtures," Journal of Hazardous Materials, vol. 56, no. 3, pp. 237-246, 1997.

[40] M. Gieras, R. Klemens, G. Rarata, and P. Wolański, “Determination of explosion parameters of methane-air mixtures in the chamber of $40 \mathrm{dm} 3$ at normal and elevated temperature," Journal of Loss Prevention in the Process Industries, vol. 19, no. 2-3, pp. 263-270, 2006. 
[41] F. Gharagheizi, "Quantitative structure-property relationship for prediction of the lower flammability limit of pure compounds," Energy \& Fuels, vol. 22, no. 5, pp. 3037-3039, 2008.

[42] E. Salzano, F. S. Marra, G. Russo, and J. H. S. Lee, "Numerical simulation of turbulent gas flames in tubes," Journal of Hazardous Materials, vol. 95, no. 3, pp. 233-247, 2002.

[43] E. S. Oran, V. N. Gamezo, and R. K. Zipf, "Large-scale experiments and absolute detonability of methane/air mixtures," Combustion Science and Technology, vol. 187, no. 1-2, pp. 324-341, 2015.

[44] V. Di Sarli, A. Di Benedetto, and G. Russo, "Using large eddy simulation for understanding vented gas explosions in the presence of obstacles," Journal of Hazardous Materials, vol. 169, no. 1-3, pp. 435-442, 2009.

[45] C. Wu and H. Hao, "Modeling of simultaneous ground shock and airblast pressure on nearby structures from surface explosions," International Journal of Impact Engineering, vol. 31, no. 6, pp. 699-717, 2005. 